\title{
Graft-Versus-Host Disease (GvHD)
}

\author{
John Murray, Jacqui Stringer, and Daphna Hutt
}

\begin{abstract}
Acute and chronic graft-versus-host disease (GvHD) is a major cause of morbidity and mortality in patients who undergo allogeneic haematopoietic cell transplantation (HCT) and affects approximately $30-40 \%$ of recipients. Its diagnosis is complicated, and staging of the disease varies dependent upon the transplant centre involved. Standardisation through the use of National Institute of Health $(\mathrm{NIH})$ guidelines helps clinicians diagnose and treat their patients more effectively. For the majority of patients who go on to develop GvHD, corticosteroids remain the first-line treatment for both acute and chronic GvHD. Recipients that are refractory to systemic steroids have a plethora of second- and third-line options available to them. A 'standard of care' approach has not yet become agreed globally due to poor evidence from small and limited randomised control trials. Supportive care is paramount, and the nurse is often at the centre of the patients care and in the best position to guide and advise the patient and family through this often long-term complication.
\end{abstract}

\section{Keywords}

Acute graft-versus-host disease $\bullet$ Chronic graft-versus-host disease

J. Murray $(\bowtie) \cdot J$. Stringer

The Christie NHS Foundation Trust, Manchester, UK e-mail: John.murray@christie.nhs.uk;

Jacqui.stringer@christie.nhs.uk

D. Hutt

Department of Paediatric Haematology-Oncology and BMT, Edmond and Lily Safra Children Hospital, Sheba Medical Center, Tel-Hashomer, Israel e-mail: dhutt@sheba.health.gov.il

\subsection{What Is GvHD?}

\subsubsection{Definitions}

Acute GvHD is a reaction of donor immune cells against host tissues. The three main tissues that acute GvHD affects are the skin, liver and gastrointestinal tract (Jacobsohn and Vogelsang 2007).

Chronic GvHD is a syndrome of variable clinical features resembling autoimmune and other 
immunologic disorders. Manifestations of chronic GvHD may be restricted to a single organ or site or may be widespread, with profound impact on quality of life (Jagasia et al. 2015).

\subsection{Background to GvHD}

The New England Journal of Medicine reported the infusion of bone marrow into patients by E.D. Thomas and colleagues in 1957, following radio- or chemotherapy. Preclinical animal studies revealed that transplantation of splenocytes from non-oncogenic donor strains facilitated haematopoietic recovery but led to a severe illness characterised by anorexia, reduced weight, diarrhoea, ruffled fur and eventual death. It was labelled at the time 'secondary' or 'runt's disease' and later became known as graft-versus-host disease (GvHD). It was clear that the effect was not one of the conditioning therapies but was associated with an immune-mediated syndrome (Wolf et al. 2012).

GvHD remains a leading cause of non-relapse mortality and is associated with a high morbidity that increasingly affects quality of life (Lee et al. 2003; Dignan et al. 2012).

However, the success of allogeneic HSCT depends on simultaneous graft-versus-tumour (GvT) effects. Therefore, broad-based immunosuppressive strategies are less attractive as these may dampen the GvT benefit. Relapse accounts for a significant proportion of treatment failures after HSCT; thus strategies for GvHD prevention with minimal impact on GvT are the holy grail of transplantation (Magenau and Reddy 2014).

Historically, GvHD is termed 'acute' before day 100 and 'chronic' any time after day 100. However, it has since been recognised that there can sometimes be 'overlap' between the types, so signs and symptoms are used to aid and determine the diagnosis. The skin is the most common organ affected followed by the gastrointestinal (GI) tract and then the liver. Typically, the skin develops a rash which often but not always appears on the palms of hands and soles of the feet first and can rapidly spread to the rest of the body. GI and liver GvHD symptoms such as nausea, vomiting, diarrhoea, abnormal liver enzymes and jaundice are similar in both acute and chronic forms of GvHD.

According to the $2014 \mathrm{NIH}$ consensus, the broad category of acute GvHD includes classic acute GvHD (maculopapular erythematous rash, gastrointestinal symptoms or cholestatic hepatitis), occurring within 100 days after HCT or donor leukocyte infusion. The broad category of acute GvHD also includes persistent, recurrent or late-onset acute GvHD, occurring more than 100 days after transplantation or donor leukocyte infusion. The presence of GvHD without diagnostic or distinctive chronic GvHD manifestations defines the broad category of acute GvHD (Vigorito et al. 2009; Jagasia et al. 2015).

\subsection{Acute GvHD}

Overview: acute graft-versus-host disease (aGvHD) occurs following an allogeneic haematopoietic stem cell transplant and is a reaction of donor immune cells against host tissues and remains a major cause of morbidity and mortality (Greinix 2008). High-dose chemotherapy +/radiotherapy inflicts cellular damage, and this leads to an inflammatory process; the activated donor $\mathrm{T}$ cells interact with the host epithelial cells. Approximately 35-50\% of haematopoietic stem cell transplant (HSCT) recipients will develop aGvHD (Dignan et al. 2012). There are several factors that can influence the development of aGvHD: the stem cell source, age of the patient, conditioning regimen and GvHD prophylaxis used. All aGvHD can be associated with culture negative fever. Commonly the three most cited organs are skin (rash/dermatitis), liver (hepatitis/jaundice) and GI tract (abdominal pain/ diarrhoea), and these may occur in isolation or in combination. Biopsies of skin and GI tissue (more rarely liver) are often obtained, although the diagnosis of aGvHD is regularly made based upon clinical signs and symptoms. A biopsy is useful to help differentiate from other diagnoses which may mimic GvHD, such as viral infection 
(hepatitis, colitis) or drug reaction (causing skin rash). The modified Glucksberg-Seattle criteria (Przepiorka et al. 1995) are widely used and give a stage and grade (grade 0-IV) for each organ and its degree of involvement. Those with grade III/IV aGvHD tend to have a poor overall outcome. Upon development of signs and symptoms, immunosuppression should be optimised. Oral or intravenous corticosteroids are frequently initiated, and although steroids remain the gold standard of initial therapy, they are effective in only $40 \%$ of patients (Weisdorf et al. 1990). Many protocols suggest a steroid treatment failure, if there is no improvement in symptoms after 3-7 days of treatment. At this point salvage (second-line), immunosuppressive therapy for which there is currently no worldwide consensus is implemented. Additional management issues are to pay attention to wound infections in skin GvHD and fluid/nutrition management in gastrointestinal GvHD. About 50\% of patients with aGvHD will eventually develop manifestations of chronic GvHD (Jacobsohn and Vogelsang 2007).

\subsection{Pathophysiology of GvHD}

GvHD happens because the donated cells are not identical to the cells of patient (the host). GvHD is the body's response, a manifestation of the fight between the T cells of the donor and host's immune system.

$\mathrm{T}$ cells are white blood cells that usually protect us against foreign bodies, like bacteria, fungi and viruses. The $\mathrm{T}$ cells in our bodies are able to recognise the proteins on the cells as either belonging to us or not belonging to us. Those that belong to us are allowed to live within us in harmony, and our immune systems do not usually (except autoimmune disorders) defend themselves against these cells.

The donated haematopoietic stem cells are closely matched (except in a haplo-identical transplant) to those of the recipient, and unless they are from an identical twin, the donor cells will express slightly different cell surface pro- teins. These small differences are recognised by the body as 'non-self', and subsequently these cells get questioned and stopped repeatedly by the body's policing or immune system.

This is the basis behind all the components of our immune system and why and how we fight any external invader trying to enter our body. The greater the differences in the tissue types, the greater the chance of the recipient developing GvHD.

In the 1960s, Billingham (1966) proposed three central tenets for the development of GvHD. The essential components are:

(i) The presence of immunocompetent cells from the donor

(ii) The inability of the recipient to reject donor cells

(iii) The histocompatibility differences between the donor and recipient

Donor T cells are now recognised as occupying a central role in mediating GvHD following interactions with activated host and donor antigen-presenting cells (APC). A complex network of cytokines, chemokines, cellular receptors and immune cell subsets then modulate T-cell/APC interactions that result in the initiation and maintenance of GvHD (Magenau and Reddy 2014).

The three phase process for aGvHD comprises:

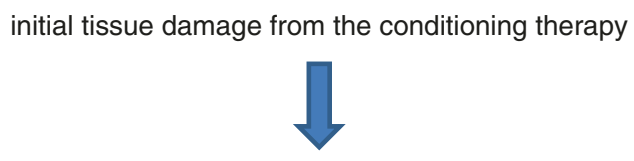

Activation of host APC

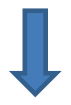

Activation and then proliferation of donor T cells

Finally, inflammatory cytokines are released such as interleukin-1 and tissue necrosis factor alpha that produce tissue necrosis. 
Fig. 11.1 The three phases of acute GVHD, as described by Ferrara and colleagues (From Hill and Ferrara 2000. Reproduced with permission)

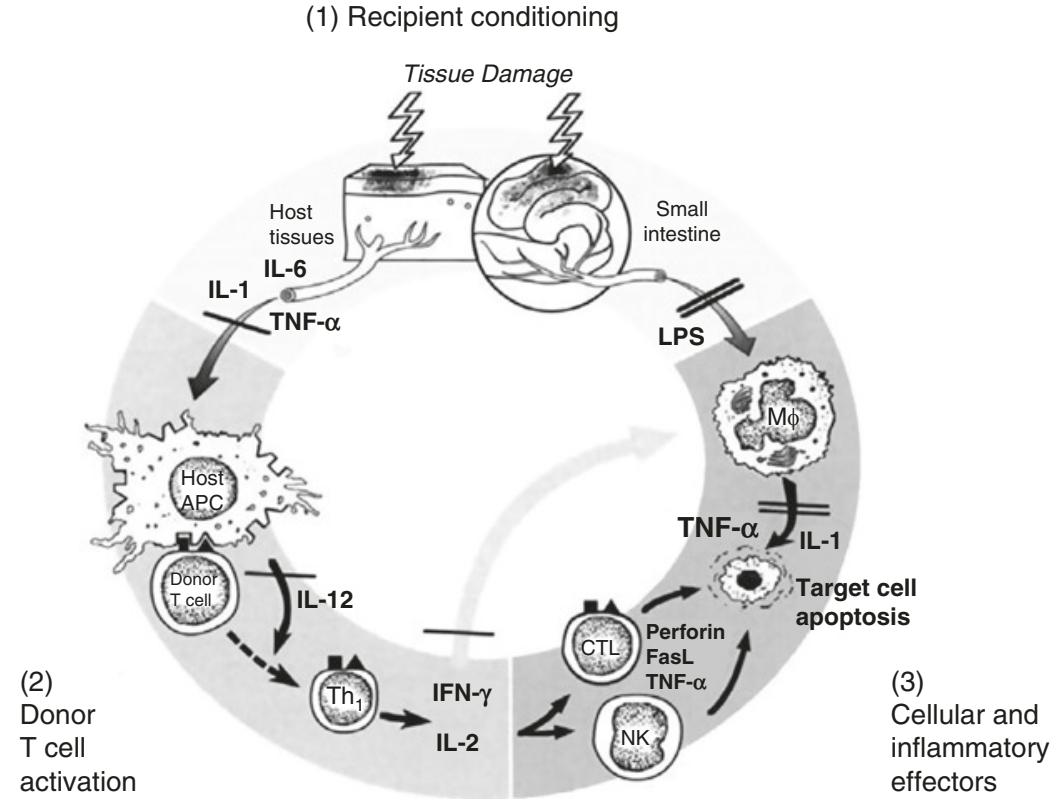

Acute GvHD is modulated in part by the presence of cells capable of inhibiting immune responses, most notably regulatory $\mathrm{T}$ cells (Magenau and Reddy 2014) (Fig. 11.1).

Both prevention and treatment of aGvHD attempt to disrupt the three-step pathophysiological cycle. Most current treatment options of aGvHD affect more than one event in this cycle through relatively non-specific immunosuppressive and anti-inflammatory mechanisms (Greinix 2008).

Reduced intensity conditioning will usually contain drugs that deplete $\mathrm{T}$ cells, such as Campath-1H or ATG. This reduces the initial risk of aGvHD but increases the risk of infective complications such as CMV and also the risk of lateonset aGvHD and chronic GvHD.

Incidence: the incidence of serious (grade III/IV) aGvHD is about $30 \%$ with a fully matched (8/8) unrelated donor but $40 \%$ with one or two allelic mismatches at class I. This compares to about a $20 \%$ incidence for recipients of HLA-identical sibling transplants (Al-Kadhimi et al. 2014).

\subsubsection{Risk Factors}

Factors that can increase the likelihood of aGvHD include older recipient/donor, sex mismatch and specifically a multiparous female donor into a male patient. Furthermore, the intensity of the preparative regimen does appear to correlate with increased incidence of aGvHD. This effect may occur due to greater tissue damage from the preparative regimen, predisposing these tissues to more inflammation from the alloreactive cells. Higher doses of radiation also gives rise to more GvHD. Equally, more recent use of nonmyeloablative preparative regimens has led to lower incidence of aGvHD in some studies (Jacobsohn and Vogelsang 2007).

\subsubsection{Signs and Symptoms of aGvHD}

Acute GvHD mainly affects the skin, gut and liver but can affect almost any part of the body.

\subsubsection{Skin}

Acute GvHD can cause a rash which is usually flat and red and often occurs on the hands, feet and around the ears and upper chest, at first. This can quickly spread to cover the whole body. It is often, but not always, itchy and sore and can feel like sunburn. A biopsy may be taken but is not always diagnostic. On examination the features may include 
apoptosis at the base of epidermal rete pegs, dyskeratosis, exocytosis of lymphocytes, satellite lymphocytes adjacent to dyskeratotic epidermal keratinocytes and perivascular lymphocytic infiltration in the dermis (Ferrara and Deeg 1991).

\subsubsection{Gastrointestinal}

Signs and symptoms include weight loss, stomach discomfort and pain, nausea, vomiting and diarrhoea. The diarrhoea can be profuse with secretions and may also result in bleeding from ulceration of the mucosa. The effects of highdose therapies and infection need to be excluded. Biopsy in this group of patients is more informative and may show apoptotic bodies at crypt bases, crypt ulceration and flattening of surface epithelium (Dignan et al. 2012).

\subsubsection{Liver}

Jaundice from hyperbilirubinaemia is the hallmark of advanced liver GvHD with a cholestatic pattern of elevated conjugated bilirubin, alkaline phosphatase and gamma-glutamyl transpeptidase (GGT) and may be associated with pruritis. There is a wide range of differential diagnoses which should be considered and excluded such as venoocclusive disease, drug toxicity and infection. It is often extremely difficult to perform biopsy due to the increased risk of bleeding, but, if taken, histology shows endothelialitis, lymphocytic infiltration of the portal areas, pericholangitis and bile duct destruction (Dignan et al. 2012).

\subsubsection{The Benefits of aGvHD}

There is a fine line with aGvHD. The symptoms and side effects can be unpleasant and sometimes harmful and, in severe cases, life-threatening. However, it is well documented that some level of aGvHD is beneficial. It has been found that relapse rates post allograft were lowest in patients with aGvHD versus those without. As mentioned earlier, a graft-versus-tumour effect exists that can be exploited. It is suspected that there are reactions to polymorphic minor histocompatibility antigens expressed either specifically on haematopoietic cells (and therefore not causing
GvHD) or more widely on a number of tissue cells that have antitumour activity, thereby preventing disease relapse (Baron et al. 2012).

\subsubsection{Classification of Acute GvHD: Grades I-IV}

Regardless of the benefits, aGvHD carries a significant transplant-related mortality (TRM) with grades $0-$ I (mild) having a TRM of approx. $28 \%$ and grade II, III and IV (very severe) TRM of $43 \% 68 \%$ and $92 \%$, respectively (Greinix 2008). Classification is performed using the revised Glucksberg-Seattle criteria (Przepiorka et al. 1995), which measures how severe signs and symptoms are in the skin, gut and liver (see Appendix 11.A.1). The treatment for $\mathrm{aGvHD}$ will depend on the grade, and the grade itself is predictive of overall survival.

\subsubsection{Prevention of GvHD}

Prophylaxis: prevention is always better than cure. Contemporary GvHD prophylaxis at most centres is based on calcineurin inhibitors (CNIs) along with short-course methotrexate (MTX). This works by interfering with calcium-dependent interleukin-2 (IL-2) gene activation and de novo purine metabolism, respectively; CNIs and MTX act synergistically to non-selectively inhibit lymphocyte activation and proliferation. The combination of ciclosporin and MTX or tacrolimus and MTX as prophylaxis for aGvHD compared to any single-agent treatment has been shown to be superior (Greinix 2008). With standard prophylaxis, approximately $40 \%$ of patients receiving HLA-matched HSCT will develop GvHD requiring high-dose corticosteroids.

\subsubsection{Drugs Used as Part of Conditioning Therapy to Prevent GvHD}

Ciclosporin $(C s A)$ : is given as an intravenous infusion commencing usually 1-2 days prior to HSCT infusion to load the blood stream and is 
eventually converted to an oral preparation when the patient is able to tolerate tablets again. Ciclosporin binds to cyclophilin and prevents generation of nuclear factor of activated $\mathrm{T}$ cells (NF-AT), which is a nuclear factor for initiating gene transcription for lymphokines including interleukin-2 and interferon gamma. This action leads to suppression of cytokine production and subsequent inhibition of T-cell activation (Greinix 2008).

Mycophenolate mofetil (MMF): used mainly in reduced intensity transplant conditioning regimens is an antimetabolite that results in noncompetitive reversible inhibition of inosine monophosphate dehydrogenase. This leads to selective inhibition of lymphocytes purine synthesis and proliferation. Patients have less mucositis and faster neutrophil recovery compared to methotrexate (Greinix 2008).

Tacrolimus: is an alternative to ciclosporin within the conditioning regimens at some centres. It binds to FK506 protein 12, a different protein to the one that CsA does but their final common pathway is identical. They both prevent the generation of NF-AT, a nuclear factor for initiating gene transcription for lymphokines like IL-2 and interferon gamma leading to suppression of cytokine production and thus inhibition of T-cell activation (Greinix 2008).

Sirolimus: is used within conditioning regimens and is a natural macrolide antibiotic that exerts its immunosuppressive effect by inhibiting cytokine-driven signalling pathways of the $\mathrm{T}$ and B cell via mTOR blockade and specifically inhibiting the progression of cells from the G1 phase to the $\mathrm{S}$ phase. The advantage is that sirolimus has a completely different toxicity profile to calcineurin inhibitors and can be used in combination with them (Dignan et al. 2012).

Methotrexate (MTX): is an anti-proliferative agent given intravenously on days 1, 3, 6 and 11 after HSCT for those patients receiving a fullintensity transplant. It prevents the division and clonal expansion of $\mathrm{T}$ cells. It is important to receive all four doses, but severe mucositis (grade IV) often prohibits administration of the 4th and final dose and is given at the clinician's discretion.
Campath 1-H or alemtuzumab: is given in a variety of doses from 30 to $90 \mathrm{mg}$ within the conditioning regimen dependent upon the cell source and degree of mismatch between donor and recipient. It is an unconjugated humanised $\mathrm{IgG} 1$ kappa monoclonal antibody that targets the CD52 antigen on the $\mathrm{T}$ and $\mathrm{B}$ lymphocytes as well as on monocytes, macrophages, eosinophils and dendritic cells. The major disadvantage of this drug is the increase of infections due to the extended period of lymphopenia. CMV reactivations and infections are particularly troublesome in this patient cohort necessitating strict surveillance (Dignan et al. 2012).

Antithymocyte globulin (ATG): decreases $\mathrm{T}$ cells and also leads to viral infections. EpsteinBarr virus (EBV) reactivations can be problematic and can result in post-transplant lymphoproliferative disease (PTLD).

\subsubsection{Initial Treatment of Acute GvHD}

Despite all of the recent advances in the understanding and treatment of GvHD, steroids remain the best and first-line therapy. The mechanism of action of steroids for aGvHD is unclear but most likely relates to the suppression of cytokines such as prevention of synthesis of interleukin-1 by antigen-presenting cells and lymphocyte activities (Greinix 2008).

Grade I: should not require systemic treatment. If CsA levels are optimised, then topical steroids in conjunction with an emollient may be introduced along with antihistamine for itchy skin. It is important, however, to ensure the emollient is acceptable to the patient and to reinforce the necessity of using the creams or lotion regularly. For a topical treatment to be effective, it must be applied. If the preparation (cream or lotion) is not liked by the patient, then compliance is poor, and it will not be effective. Precautions such as avoiding scented soaps and perfumes can minimise the risk of additional skin irritation. Reminders to maintain a good fluid intake to avoid dehydration are important as are prompts to wear natural clothing next to the skin - silk, for example, is relatively non-irritant and thermoregulating. 
Grade II: anything at or above grade II is likely to require systemic treatment. If the patient progresses from grade I to grade II following optimisation of CNI and topical therapy, then systemic corticosteroids are indicated. Patients presenting with grade II signs should commence systemic steroids for their antiinflammatory properties. The starting dose is open to discussion, and local guidelines should be followed. Some patients with GI symptoms may benefit from budesonide as a steroid-sparing treatment as it is regarded as a non-absorbable therapy.

Grades III and IV: requires treatment with systemic steroids. If GI symptoms are the major feature, then the steroids should be given intravenously to prevent problems with absorption because of vomiting, diarrhoea and abnormal mucosal lining.

Steroids were first seen to be an effective treatment in the 1980s and remain effective globally in approximately $40 \%$ of people, with $30 \%$ having a long-lasting response and a probability of survival at 1 year of $53 \%$. The skin being the most responsive at $40 \%$ with a response rate of $15-35 \%$ for those with liver involvement and $45 \%$ in GI. The lower the grade of aGvHD and the fewer organs affected result in a better response to steroids. There is currently no standard time for assessing the effectiveness of the steroids with a time gap of 3-7 days often given as indicative of treatment failure and requiring escalation to second-line therapies. The GvHD may at this point be labelled as 'steroid refractory disease' which carries a dismal long-term prognosis (Magenau and Reddy 2014) with infection being the leading cause of mortality followed by organ failure in nonresponders (Greinix 2008). Below is a list of second- and third-line treatment options for those who have had their CNI optimised and have failed to respond to corticosteroids for at least 7 days. The evidence for many of the second- and thirdline treatments is sparse and comes from small patient series with heterogeneous populations. If patients fail a second-line therapy, then a further second-line therapy should be tried before moving on to third-line options (Dignan et al. 2012). Long-term survival has not been improved fol- lowing addition of second-line treatments in comparison to steroids alone (Greinix 2008).

\subsubsection{Second-Line Therapies for aGvHD}

Extracorporeal photopheresis: 8-methoxyp soralen (8-MOP) is a photoactivated drug that covalently binds to DNA pyrimidine bases, cell surface molecules and cytoplasmic components in the exposed nucleated white cells causing a lethal defect. It is added to a patient's blood following withdrawal by a cell separator; this is then exposed to ultraviolet light A (UVA) and returned to the patient. The blood is separated into buffy coat as well as red cells and plasma, which are returned to the patient. The buffy coat is exposed to the UVA in the presence of the 8-MOP. Once reinfused, the cells undergo apoptosis over the next 24-48 h (Greinix 2008).

The mechanism of action is not currently fully understood but may relate to apoptosis of leucocytes. When the cells are reintroduced into the patient, they continue to phagocytose. The reinfusion of these cells and subsequent phagocytosis by antigen-presenting cells (APCs) may regulate immune homeostasis through modulation of cytokine production and tolerance induction of APCs (Bladon and Taylor 2006). This possible mechanism of ECP-induced immune tolerance includes inhibition of pro-inflammatory cytokine secretion, increased secretion of antiinflammatory cytokines, reduced stimulation of effector T cells, induction of accelerated death of effector cells and stimulation of regulatory T-cell generation (Greinix 2008). ECP is a safe treatment as it has fairly minimal side effects, hypotension, fevers, drop in haemoglobin, photophobia and tiredness post procedure. The procedure is performed in most centres by highly trained apheresis nursing staff. The patient is assessed and accepted onto the ECP service following local policy. Venous access is assessed, and if this is inadequate via the antecubital fossa, a central venous catheter will be placed.

Further second- and third-line therapies include: 


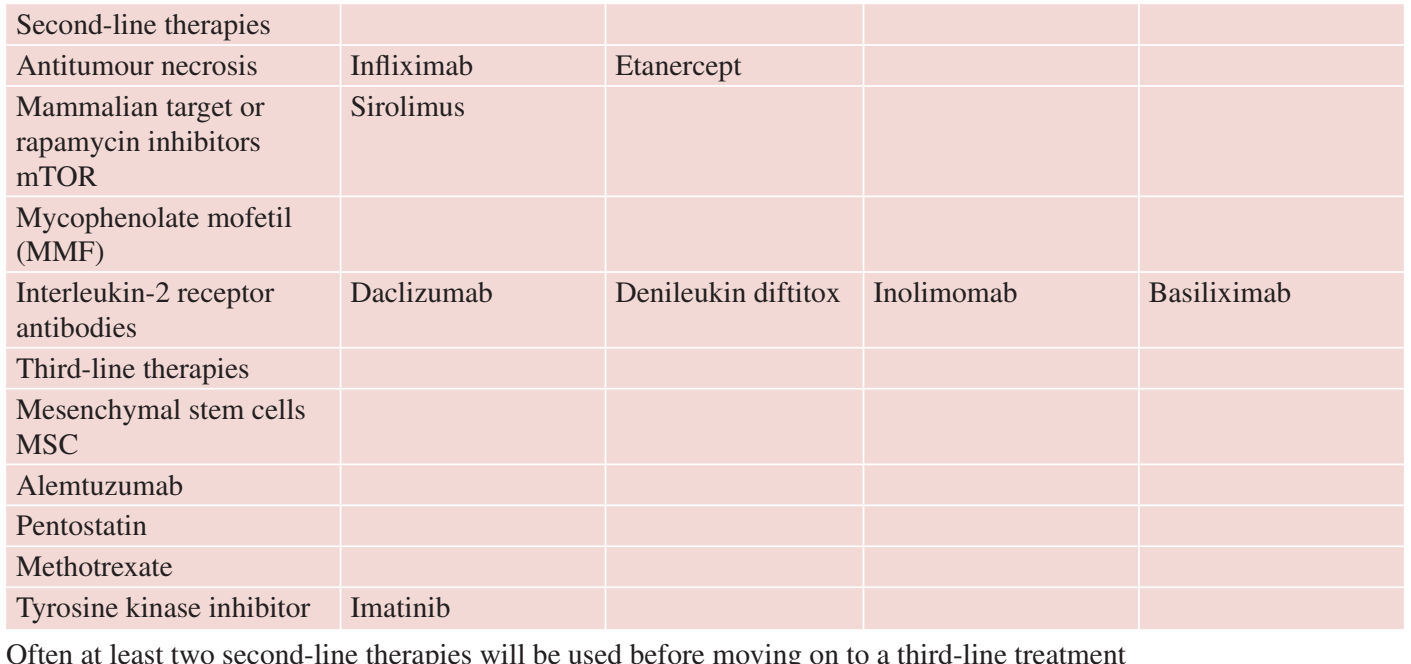

\subsubsection{Nursing Care Considerations for aGvHD}

In addition to systemic treatments, there are often topical management techniques as well as general care that nurses can offer to patients that will lead to relief from frequently troublesome symptoms of aGvHD. Below are a few pointers for consideration when seeing patients with aGvHD affecting their skin, gastrointestinal system, eyes, mouth or genitals.

\subsubsection{Cutaneous}

\section{Basic skin care:}

The key issue with patients who have cutaneous aGvHD is to maintain the integrity of the skin, and the following suggestions are key factors in doing this: Regular application of preferred emollients (e.g. QV, Hydromol, Diprobase). Advise application of a thin layer (enough to make the skin appear 'shiny'), in the direction of hair growth. Try not to 'rub' as this will increase any pain or itch. As guidance for amounts, it would be suggested that an adult would use on average $500 \mathrm{~g} /$ week and a child, $250 \mathrm{~g} /$ week. Use of bath/shower preparations (e.g. Dermol, QV, Hydromol) rather than soap, use of high SPF sun- screen (e.g. SunSense SPF 50+) and localised use of topical antipruritic agents (e.g. Dermacool $0.5-1 \%$ ) if required. If the skin is still flaky, the patient can be advised to apply lipids (e.g. coconut oil) in addition to the emollients. Topical immunomodulation (e.g. steroid/tacrolimus cream) should be prescribed as per local protocol; however, there are a few general rules about the use of topical steroids: think about the potency/ duration of the product used in relation to the age of the patient and the area of the body it is being applied to. Always apply thinly - once daily is usually enough. Think about whether the skin is weepy, when a cream/lotion is appropriate or dry/ scaly in which case an ointment may be preferable. Steroids should be applied at a different time to emollients (at least a 30 minute gap between) to ensure effective absorption and remember that broken skin is a contraindication to use.

Topical management of specific stages of cutaneous aGvHD:

1. Maculopapular rash (pruritic/painful). Most common areas: soles of feet, palms of hands, cheeks, ears, neck, trunk and upper back.

Emollients are key to management at this stage. With sensitive, irritated skin, an emollient which is too thick will just not be used, whereas 
one which is too 'thin' will be perceived as ineffective. It is worth offering sample packs with a variety of products to trial, either made up by the hospital or provided by a specific company (e.g. QV products by Crawfords). In situations where pruritis is a major issue, a product with high water content can be useful as they are more cooling but will need regular application.

Topical steroids, each hospital will have its own protocol for prescription of topical steroids and this should be adhered to.

Menthol cream (0.5-1\%, e.g. Dermacool), these products can be useful for management of painful and pruritic skin but must be used with care as they can make the patient feel very cold with widespread use so are better used only on focal areas of extreme itch/pain.

Medical grade silk clothing (e.g. Dermasilk, Espere Healthcare), it is important to explore the holistic care of the patient. Many clothing materials can cause irritation - even natural materials such as cotton. If there are widespread areas of the torso affected, it is worth suggesting the use of medical grade silk as this is manufactured to cause minimal irritation and, in some countries, can be prescribed. If this is not available, clothing made from bamboo can be suggested as an alternative.

2. Erythroderma: intense generalised redness of the skin; inflammation that gives rise to erythema and scaling all over the body. Classically involves greater than $90 \%$ of the body surface.

The topical management of erythroderma is similar to the advice mentioned above, with emphasis on the regular application of easily applied emollients and increasing fluid intake. However, because erythroderma is so widespread, the use of menthol creams is limited unless there are specific areas of the body which are causing particular distress.

In addition to the products above, in an attempt to maintain skin integrity, organic coconut oil or other natural lipids (e.g. olive oil) can be useful supplements to the emollients. Equally good quality creams containing aloe vera gel are often very soothing (note: do not use aloe vera gel alone as this will dry the skin).

3. Bullous/desquamation (stage IV): formation of large blisters and separation of the dermis/ epidermis from the basal layer causing massive fluid loss.

These patients need treating as a person with severe burns. Your hospital may have a protocol specifically for this but an example would be to irrigate with sterile water, apply an antibacterial cream (e.g. Flamazine) and protect the area from the air to minimise pain and risk of infection. The cream can be applied directly to sterile theatre gauze and wrapped around the patient to prevent trauma.

\subsubsection{Oral}

Patients with oral aGvHD complain of a sore mouth that is not dissimilar to the pain suffered with oral mucositis post chemotherapy/radiotherapy. Tolerance of spicy food stuff is poor, toothpaste burns and hot drinks such as tea and coffee are almost impossible to take. It is important to rule out infection as this will cause pain to be worse. Frequent swabs for virus, bacterial and fungal infection should be taken and acted upon promptly. To aid with oral pain management, the use of caphosol, Gelclair, lidocaine, paracetamol mist and Difflam mouth wash can be used.

Advise patients to frequently swill the mouth after eating to remove any debris using plain water. This is refreshing and ph7 so comfortable to do. Encourage the use of products to aid production of saliva as the mucosa is usually very dry. Artificial saliva or sugar-free gum and in some centres pilocarpine may be used.

Many medications have side effects of dry mouth. Look to see if there are any alternatives that could be prescribed for your patient.

Early referral to the dentist is vital as the risk of dental caries and secondary oral cancers is higher in patients with oral GvHD. Advice to perform regular oral exercises to reduce the risk of contractures. 


\subsubsection{Gastrointestinal}

Patients who develop diarrhoea will have stool samples sent to exclude infective components. Once ruled out and treatment started, nursing care may aid in a more rapid recovery and maintenance of weight. Ensuring an adequate oral input with high-calorie supplements, strict fluid balance is of primary importance. The options of enteral feeding or intravenous total parental nutrition in the short term to rest the bowel need to be kept in mind if the above actions are not sufficient, with procedures such as a radiologically inserted gastrostomy (RIG) used for longterm issues. Those with upper GI disturbance, nausea and vomiting need advice on small and frequent meals as well as supplements. Patients who develop grade IV GI aGvHD will benefit from use of flexi-seal faecal collection devices.

\subsubsection{Eyes}

Patients with dry and gritty eyes will benefit from regular and frequent use of lubricating eye drops. Infection should be excluded and treated if apparent. Wearing dark glasses will reduce irritants such as wind and block any debris that it may blow into the patient's eyes. There are a variety of graded dark glasses that may be obtained through an optician that can block up to $90 \%$ of light and reduce photophobia significantly. It is often useful to wear glasses inside the house to reduce discomfort. Cold compress with ice packs and chamomile tea bags are useful in some instances.

\subsubsection{Genito-urinary System}

This is an under-reported area of GvHD from patients; some basic nursing input can help with symptoms of pain and discomfort experienced. Asking patients if this is a problem for them is the first step as patients are often reticent about mentioning genital problems to the medical team. Once infection has again been ruled out or treated, there are a variety of treatments that may offer some symptomatic benefit. With female patients, application of an emollient to the vulval region and use of dilators with a lubricant such as olive oil or coconut oil will help to minimise the risk of contractures. Vaginal moisturisers may make women feel more comfortable. Referral through to endocrinology for discussions about hormone replacement therapy (HRT) with oestrogen can be initiated by nursing staff. Men may mention tightening of the foreskin and gentle frequent retraction, and application of emollient is suggested alongside good hygiene.

\subsection{Chronic Graft-Versus-Host Disease}

The understanding of the pathophysiology of chronic graft-versus-host disease (cGvHD) is in its infancy, and progress to prevent and treat cGvHD remains limited (Greinix 2008). Chronic GvHD remains the major cause of late morbidity and mortality after allogeneic haematopoietic cell transplantation and is a serious and common complication occurring in $20-80 \%$ of patients (Lee and Flowers 2008). Chronic GvHD prevalence and severity has increased over the past 20 years in line with the increasing use of haematopoietic stem cell transplantation for treatment of older age patients, the widespread use of mobilised blood cells instead of marrow for grafting and improvements in survival during the first several months after allograft. Typically occurring in the first 12 months, it can be seen as early as 2 months and as late at 7 years at onset, although onset at $>1$ year from transplant occurs in $<10 \%$ of cases (Flowers and Martin 2015). The risk of infection due to the delay in immune reconstitution and use of immunosuppressive therapies to treat $\mathrm{cGvHD}$ remains, however, the leading cause for death in this group of patients (Couriel et al. 2006b). Supportive care advances have decreased the morbidity, but survival has not changed significantly since the 1980s. Patients with cGvHD have a 5-year survival of $40-70 \%$ with only $50 \%$ being able to stop immu- 
nosuppression at 5 years, with $10 \%$ needing treatment beyond this time point. The other $40 \%$ either die or develop a further malignancy before cGvHD resolves (Martin et al. 2006).

As cGvHD only occurs in allografted patients and can be prevented by T-cell depletion from the donor graft, donor $\mathrm{T}$ cells responding to allogeneic antigens in the patient are of critical importance in the development of cGvHD (Kuzmina et al. 2011). Chronic GvHD was initially thought to be as a consequence of persistent recognition of antigenic tissue differences between donor and host. However, the role of alloreactivity versus autoreactivity in the pathogenesis of cGvHD remains an area of debate (Greinix 2008).

Meier et al. (2011) explain that:

\begin{abstract}
Donor-derived immunocompetent $\mathrm{T}$ cells react directly or through exaggerated inflammatory processes against tissue after allograft. The persistence of alloreactive T cells, a Th1-Th2 shift of the cellular immune response (cGvHD seems to be mediated prominently by the Th2 cytokine response), defective peripheral and central tolerance mechanisms (i.e. failure of control by regulatory $\mathrm{T}$ cells and /or impaired negative selection of $\mathrm{T}$ cells in the thymus), replacement of antigen presenting cells (APC) of the host by APC's of the donor leading to indirect antigen presentation of allo-antigens, an increasing role of B cells producing auto and allo-antibodies against the host and non-specific mechanisms of chronic inflammation leading to fibrosis of involved organs.
\end{abstract}

The importance of autoreactivity is suggested by clinical manifestations of cGvHD that frequently mimic those of autoimmune diseases, as well as the finding of autoantibodies derived from B cells after Th2-mediated stimulation and cytokine release (Greinix 2008).

The advances in understanding of this process will have an impact on patients overall survival. Using a multidisciplinary team approach for best care, identifying those at risk, monitoring, early recognition with prompt diagnosis and highquality follow-up with an agreed management plan to prevent complications of therapy that can often lead to disabilities are vital to continue to make headway in this immensely challenging area (Flowers and Martin 2015).

\subsection{Acute Vs Chronic GvHD}

Historically if patients developed signs and symptoms of GvHD after day 100, this was labelled as chronic even if clinically the patient appeared to have acute features. The criteria for the diagnosis of $\mathrm{cGvHD}$ are based on pathological changes occurring in the skin, lung, mucous membranes, gastrointestinal tract and musculoskeletal system (Greinix 2008). The National Institute of Health $(\mathrm{NIH})$ developed a set of criteria following a consensus meeting in 2005 to help address the problem of diagnosis and wrote several guidelines on the diagnosis and classification of chronic GvHD. They stated that acute and chronic GvHD should be distinguished by clinical features rather than time from transplant. There should be the presence of at least one diagnostic clinical sign of cGvHD or presence of at least one distinctive manifestation confirmed by pertinent biopsy or other relevant test. All other diagnoses should be excluded (Filipovich et al. 2005).

The broad category of cGvHD includes classic cGvHD; presenting with manifestations that can be ascribed only to cGvHD, however, it also includes an overlap syndrome, which has diagnostic or distinctive cGvHD manifestations together with features typical of aGvHD (Vigorito et al. 2009).

It is no longer useful to simply describe cGvHD as limited or extensive based on the number of organs involved as this was a system devised in 1980 following the study of 20 patients in a retrospective review (Shulman et al. 1980). A more reliable and reproducible scoring scheme was described to evaluate the individual organ severity over four grading scores $0-3$ by the NIH:

- None; score 0

- Mild involvement (no significant impairment of daily living); score 1

- Moderate involvement (significant impairment of daily living); score 2

- Severe impairment (major disability); score 3

The clinical score describes how affected the patient is by their inability to perform activities 
of daily living. This evaluation covers the involvement of individual organs and sites. For example, if they are unable to work due to ocular loss, they would be scored as 3 severe (Carpenter 2011). The scoring should be undertaken initially at 3 months post-transplant and at 3 monthly intervals and more frequently if new signs or symptoms are found or there is a change in treatment.

The NIH in 2014 provided a further update with the Diagnosis and Staging Working Group Report. Following new evidence, refinements were made to address the areas of controversy or confusion such as overlap and classic chronic GvHD. The subcategories of 'overlap' as it was transient and often depended on the degree of immunosuppression and is subject to changes during the disease course and 'classic' cGvHD as patients may develop acute features when immunosuppression is tapered were removed. A revision was made to the diagnostic criteria for involvement of the mouth, eyes, genitalia and lungs. Schirmer's test has been removed from the severity scoring form, and an ophthalmology review is recommended. Also if an unequivocal explanation can be made for a specific abnormality that is not GvHD, then that organ should be regarded as not affected by GvHD (Jagasia et al. 2015).

Chronic GvHD commonly occurs in patients who have previously had aGvHD although it is not simply a case of evolution from one to another. Chronic GvHD usually occurs within 3 years of allograft and is a disease of deregulated immunity with protean manifestations that mimic autoimmune disorders such as Sjogren syndrome, primary biliary cirrhosis, wasting syndrome, bronchiolitis obliterans, immune cytopenias and chronic immunodeficiency (Jagasia et al. 2015).

Due to the ambiguity of diagnosis, the limited understanding of pathophysiology and the additional clinical complexities that accompany this group of patients, a systematic approach to management has been somewhat lacking (Couriel et al. 2006a). There is still no unified consensus on the diagnostic features, although recent work from the NIH (2014) has in some ways addressed this with an attempt to bring a standardised assessment to clinical practice.
Presentation with signs and symptoms of cGvHD nearly always occurs within the first year post allograft but can occasionally happen several years later. Single organs alone may be affected and can progress to other organs; however, cGvHD nearly always affects multiple sites, having major impact upon a patient's quality of life. The eyes, mouth, skin, GI tract and liver are the most frequently affected organs. There is a wide range in severity and how this relates to compromise in patients' QoL, with some manifestations being more problematic to treat. Fasciitis or cutaneous sclerosis, severe ocular sicca and bronchiolitis obliterans syndrome (BOS) often require extensive periods of time with multiple immunosuppressive agents to treat (Flowers and Martin 2015).

\subsubsection{Diagnosis of cGvHD}

For a diagnosis of cGvHD to be made, the NIH 2014 working group suggest that at least one diagnostic manifestation of cGvHD or at least one distinctive manifestation, with the latter confirmed by pertinent biopsy, laboratory tests, evaluation by a specialist or radiology in the same or other organ, be present, unless stated otherwise. It is important with any organ considered for a diagnosis of $\mathrm{cGvHD}$ that other causes for the symptoms are excluded such as infection, recurrent or new malignancy (Jagasia et al. 2015). The features should also differ from the typical dermatitis, enteritis and cholestatic liver manifestations of aGvHD (see Appendix 11.A.2 for the full tables of assessment).

\subsubsection{Chronic GvHD of the Skin}

In cGvHD the skin is the most frequently affected organ if the patient has received HCT and has a wide variety of manifestations (Pavletic et al. 2006). For a clinical diagnosis of skin cGvHD features of poikiloderma, lichen planus-like eruption, deep sclerotic features, morphea-like superficial sclerotic features or as lichen sclerosus-like lesions are needed (Jagasia et al. 2015). 
Assessments of skin are performed to look at the four anatomic levels of involvement, and the score is based on the percentage of area involved and the differentiation between non-sclerotic and sclerotic features:

1. Erythematous rash (epidermal involvement)

2. Movable sclerosis (dermal involvement)

3. Non-movable sclerosis, hidebound skin or involvement of subcutaneous tissue and facia (subcutaneous involvement)

4. Ulceration (full-thickness loss of epidermal tissue)

Points 1-3 are assessed using the 'rule of 9s' body surface area score. Local skin involvement below $20 \%$ body surface and the absence of sclerotic features is classified as 'mild'. Skin involvement between $20 \%$ and $50 \%$ is 'moderate' with more than $50 \%$ becoming 'severe' (Greinix 2008). This scoring system is effective in adults but less so in children; however, it is still used in children over the age of 1 year. Ulceration is recorded by measuring the diameter of the largest ulcer (Pavletic et al. 2006). The skin is often very fragile and becomes damaged easily with poor healing of any wound. Distinctive features of cGvHD that are not seen in aGvHD are depigmentation although this occurs gradually and may only be perceptible over long time periods and papulosquamous lesions, although this alone is not enough for a diagnosis. It must be made in combination with other signs or confirmed with biopsy. Common features of both acute and chronic GvHD are erythema, maculopapular rash and pruritis (Jagasia et al. 2015). Itching is common and, therefore, should be recorded using a scale of 1-10 for severity with the patient asked what was the highest score this week (Pavletic et al. 2006).

Distinctive signs of nail cGvHD are longitudinal ridging, splitting or brittleness, onycholysis and loss of nails that is usually symmetric and affects most nails (Jagasia et al. 2015).

Loss of hair can be a devastating effect of cGvHD for patients, and in this context it is considered a distinctive feature alone. Hair has often returned following chemotherapy or radiother- apy, and the loss is often patchy and happens across the whole body. Patients may suffer with premature greying, thinning or brittleness of their hair (Jagasia et al. 2015).

\subsubsection{Chronic GvHD of the Oral Cavity}

For patients who have received stem cells derived from the bone marrow (BM), oral cGvHD is the most common site of involvement, and the oral cavity is the second most common site with PBSC (Meier et al. 2011). There are three components to mouth and oral mucosa assessment:

1. Mucosal involvement

2. Salivary gland involvement

3. Sclerotic involvement of mouth and surrounding tissues (Couriel et al. 2006b)

Within the oral cavity clinical diagnostic features include lichen planus-like changes. These are described as white lines and lacy-appearing lesions or plaque like changes. This can occur on any oral surface including the tongue and lips. The mouth will be dry (xerostomia) and have mucoceles, mucosal atrophy, ulcers and pseudomembranes. Common features of both acute and chronic GvHD are gingivitis, mucositis, erythema and pain (Jagasia et al. 2015). If new lesions occur $>3$ years post-transplant, secondary malignancy should be excluded with biopsy. The lesion often starts as leukoplakia and can be confused with cGvHD but may be a squamous cell carcinoma (SCC) (Couriel et al. 2006b).

Chronic GvHD of the mouth is scored on three areas using the standard 0-3 scale with a percentage of area involved:

\section{Erythema \\ 2. Lichenoid \\ 3. Ulcers}

Oral sensitivity is measured on a self-score system from 1 to 10, with worst it has been for the past week (Pavletic et al. 2006). The consequences of oral cGvHD in cases of hypo- 
salivation and xerostomia are in relation to the function of saliva and lack thereof. Poor protection against oral infections and mechanical and chemical epithelial injuries can occur. Remineralisation is impaired that can lead to dental caries, speech may be altered and eating becomes problematic (Meier et al. 2011; Treister et al. 2013).

\subsubsection{Chronic GvHD of the Eyes}

New onset of dry, gritty or painful eye with cicatricial conjunctivitis, keratoconjunctivitis sicca and confluent areas of punctate keratopathy are distinctive features and may occur in isolation with no other active cGvHD (Couriel et al. 2006b). Lacrimal dysfunction or destruction is responsible for dry eye symptoms (Pavletic et al. 2006). Patients may describe photophobia, burning, irritation; pain, a foreign body sensation, blurred vision and paradoxically excessive tearing. Scoring of eyes is based on frequency of use of eye drops and the occurrence of keratoconjunctivitis sicca. Asymptomatic keratoconjunctivitis sicca or need for eye drops less than three times per day is classed as 'mild', whilst symptomatic and the need for more than three times daily eye drops $+/-$ punctual plugs is 'moderate'. Those with 'severe' ocular cGvHD are unable to work because of ocular symptoms or require special eyewear to relieve pain or have loss of vision due to keratoconjunctivitis sicca (Greinix 2008).

\subsubsection{Chronic GvHD of the Genitalia}

Patients who suffer from oral cGvHD are also very likely to have some degree of genital cGvHD. This affects both men and women and is significantly under-reported. In women vaginal scarring and clitoral/labial agglutination occur, and in men phimosis and urethral/meatus scarring are features. In both sexes, lichen planus-like and lichen sclerosis features are diagnostic. It is essential due to the under-reporting of symptoms that patients are examined for early signs especially if oral features are present. Studies suggest that $3-15 \%$ of women have vulvar or vaginal cGvHD (Couriel et al. 2006b). The diagnosis relies heavily on sign and symptom reporting. Symptoms in women may include dryness, burning, pruritis, pain to touch, dysuria and dyspareunia. Signs include patchy or generalised erythema, mucosal erosions or fissures, labial resorption, circumferential fibrous vaginal banding, vaginal shortening and complete vaginal stenosis. Female genital tract involvement is scored as 'mild' if any erythema on vulvar mucosal surfaces, vulvar lichen planus or vulvar lichen sclerosis exists. Those with any erosive inflammatory changes of the vulvar mucosa or fissures in the vulvar folds are scored as 'moderate'. Severe scores are when there is labial fusion, clitoral hood agglutination, fibrinous vaginal adhesions, circumferential fibrosis vaginal banding, vaginal shortening, synechia, dense sclerotic changes and complete vaginal stenosis (Couriel et al. 2006b).

In the absence of diagnostic manifestations of cGvHD in other organs, histological evidence is strongly recommended and ruling out of oestrogen deficiency or infection with yeast, HPV or bacteria (Couriel et al. 2006b). A referral pathway to the gynaecologist and if possible one with an interest in assessing these patients should be implemented.

Men may have painful intercourse and a burning sensation on micturition. Signs include noninfectious balanoposthitis, lichen sclerosis-like or lichen planus-like features, phimosis or urethra or meatus scarring or stenosis (Jagasia et al. 2015). Signs of lichen planus-like features are classed as 'mild', lichen sclerosis-like features or moderate erythema is 'moderate', and 'severe' signs are phimosis or urethral or meatal scarring.

\subsubsection{Chronic GvHD of the Gastrointestinal (GI) Tract}

Gastrointestinal tract symptoms occur frequently, and oesophageal web, stricture or concentric rings demonstrated on endoscopy or imaging are diagnostic features for GI cGvHD. Patients may have dysphagia, odynophagia, heartburn, 
anorexia, nausea, vomiting, abdominal pain, cramping, diarrhoea, weight loss and malnutrition, and these are all common features present in both acute and chronic GvHD as well as other aetiologies. It is important to make a firm diagnosis before commencing treatment. Diarrhoea should be investigated with stool culture and virology examination to exclude $C$. diff and CMV in particular (Couriel et al. 2006b). Patients may also suffer from pancreatic atrophy and exocrine insufficiency that causes malabsorption and can respond to pancreatic enzyme supplementation (Jagasia et al. 2015). For upper GI, early satiety, anorexia or nausea and vomiting are scored on occasional symptoms with little reduction in oral intake during the past week being 'mild'; a 'moderate' score of cGvHD as intermittent symptoms with some reduction in oral intake during the past week; and 'severe' if the patient has persistent symptoms throughout the day with a marked reduction in oral intake on almost every day of the past week. Lower GI disturbance with diarrhoea will score 'mild' if the patient has occasional loose or liquid stool on some days throughout the week. If the patient is having intermittent loose or liquid stool throughout the day, on almost every day of the last week without requiring intervention to prevent or correct volume depletion scores as 'moderate'. Those with 'severe' disease have voluminous diarrhoea on almost every day of the past week requiring intervention to prevent or correct volume depletion.

\subsubsection{Chronic GvHD of the Liver}

The liver has no firm diagnostic features of cGvHD, and all other causes need to be excluded, e.g. viral infections, biliary obstruction and drug toxicity. A biopsy if possible can help but carries a high risk of bleeding and is therefore not frequently performed; imaging may be useful to exclude liver abscess, infiltration or gall bladder disease (Couriel et al. 2006b). Patients may present in two ways, with a liver function test showing a steep rise in serum ALT, with or without jaundice or transaminitis, or as a progressive cholestatic picture with elevation of serum alkaline phosphatase and GGT followed by jaundice (Jagasia et al. 2015). Any elevation of liver enzymes greater than twice normal may be regarded as 'mild', 2.5 times upper limit of normal as 'moderate' and 'severe' if five times.

\subsubsection{Chronic GvHD Pulmonary System}

Historically for a firm diagnosis of pulmonary cGvHD, a biopsy was essential to prove bronchiolitis obliterans (BO); however, as there was a high risk of bleeding, it is now accepted that a diagnosis of bronchiolitis obliterans syndrome (BOS) can be made following pulmonary function testing (PFT). Pre-transplant screening is essential to obtain a baseline PFT with posttransplant PFT at 3 months and 1 year or more frequently if the patient develops signs as patients remain asymptomatic with an insidious onset of symptoms (Flowers and Martin 2015). A new onset of an obstructive lung defect is indicative of BOS. Clinically the patient may be short of breath on exertion and have a cough or wheeze, but these may be later effects. There are strict criteria for BOS and all need to be met for a diagnosis:

1. FEV1/VC $<0.7$ or the 5th percentile of predicted.

(a) $\mathrm{FEV} 1$ = forced expiratory volume in $1 \mathrm{~s}$.

(b) $\mathrm{VC}=$ vital capacity (forced vital capacity (FVC) or slow vital capacity (SVC), whichever is greater).

(c) The 5th percentile of predicted is equivalent to the lower value of predicted confidence interval.

(d) For paediatric patients or elderly populations, use $<$ predicted confidence interval using NHANESIII calculations.

2. $\%$ FEV $1<75 \%$ of predicted with $>10 \%$ decline over less than 2 years. \%FEV1 should not correct to $>75 \%$ with salbutamol, and the rate of decline for the corrected values should still remain at $>10 \%$ decline over 2 years. 
3. Absence of infection in the respiratory tract, documented with investigations directed by clinical symptoms, such as radiologic studies (radiographs or computed tomographic scans) or microbiologic cultures (sinus aspiration, upper respiratory tract viral screen, sputum culture, bronchoalveolar lavage).

4. Either one distinctive manifestation of chronic GVHD or another supporting feature of BOS.

Air trapping by expiratory chest highresolution $\mathrm{CT}$ or small airway thickening or bronchiectasis or trapping on PFT where there is a residual volume of $>120 \%$ or residual volume/ total lung capacity $>120 \%$ predicted is supporting evidence for BOS (Jagasia et al. 2015).

\subsubsection{Chronic GvHD of the Musculoskeletal System}

Diagnostic features of the musculoskeletal system include fascial involvement usually of the forearms or legs, but frequently affecting the abdomen and chest wall with sclerosis of the overlying skin and subcutaneous tissue and joint stiffness or contractures that can develop and severely impact on quality of life (Jagasia et al. 2015). The degree of functional impairment is scored as 'mild' if there is mild tightness of arms or legs, normal or mild decreased range of movement (ROM) and does not affect activities of daily living (ADL). Where there is tightness of arms or legs or joint contractures, erythema thought due to fasciitis, a moderate decrease of ROM and mild to moderate limitation of ADL scores as 'moderate'. For 'severe' then the patient will have contractures with significant decrease of ROM and significant limitation of ADL, e.g. unable to tie shoe laces, button a shirt or dress self.

\subsection{Scoring of Chronic GvHD}

The global scoring system of NIH 2014 was developed to be suitable for clinical trial assessments and reflects the clinical impact of cGvHD on the
Table 11.1 NIH global severity of chronic GvHD

\section{Mild chronic GvHD}

1 or 2 organs involved (not lung) plus

Score in involved organs 1 plus

Lung score 0

Moderate chronic GvHD

3 or more organs involved plus

Score of 1 in each organ

OR

Atleast 1 organ (not lung) with a score of 2 OR

Lung score 1

Severe chronic GvHD

1 organ with a score of 3

$O R$

Lung score of 2 or 3

Key points

1. In skin: Higher of the two scores to be used for calculating global severity.

2. In lung: FEV1 is used instead of clinical score for calculating global severity.

3. If a non-GvHD documented cause unequivocally explains the entire organ abnormality, then the organ is not scored for global severity. If the abnormality is thought to be multifactorial, it is scored without attribution from non-GvHD causes.

Jagasia et al. (2015) with permission

patient's functional status and organ impairment and is defined by Jagasia et al. 2015 as (Table 11.1):

\subsection{Assessment of Response}

Pavletic et al. (2006) proposed a set of measures for assessing the response to treatment of $\mathrm{cGvHD}$ patients. These should be performed at 3 monthly intervals or whenever a major change occurs. Organ-specific measures should be recorded from clinical signs and symptoms, and a global rating of mild/moderate/severe made. Assessment with non-specific ancillary measures such as grip strength, 2-min walk test (or Activity Scale for Kids (ASK)) and Karnofsky score with a quality of life score (QoL) are recommended. Quality of life assessment tools such as SF-36 or FACT-BMT in adults or CHRIs (Child Health Ratings Inventories) in children can be used. 


\subsection{Treatment of Chronic GvHD}

The long-term aim of cGvHD therapy is for the patient to develop immune tolerance and reduce the morbidity. This is recognised by the ability to withdraw immunosuppression without a flare of symptoms. Most therapeutic options focus on the development of immunosuppressive agents and the ex vivo removal of the unfractionated donor T-cell population from the stem cell graft (Greinix 2008). The mainstay of treatment has for more than 30 years been the use of systemic steroids, usually with a starting dose of $1 \mathrm{mg} / \mathrm{kg}$ per day with or without calcineurin inhibitor (CNI). Steroids have a multitude of side effects such as toxicities, diabetes, weight gain, bone loss, myopathy, hypertension, mood swings, cataracts, avascular necrosis and an increase in infections (Flowers and Martin 2015).

Treatment for cGvHD is far from satisfactory with only approximately $50 \%$ of patients responding to systemic steroids with or without calcineurin inhibitors and less than $20 \%$ of patients alive without disability at 4 years. Combinations of steroids with azathioprine, thalidomide, mycophenolate mofetil or hydroxychloroquine in randomised trials have not yielded any benefit over steroids alone for survival or duration of therapy (Flowers and Martin 2015). Despite this, steroids still offer the best first-line treatment choice for those with cGvHD and should be started as soon as a diagnosis is made.

There are a number of second-, third- and fourth-line therapies available, and approximately $50 \%$ of patients will require alternatives within 2 years of initial therapy due to progression of cGvHD (Flowers and Martin 2015).

\subsubsection{Second-Line, Third-Line and Other Therapies for Chronic GvHD}

Below is a brief list of second- and third-line therapies for cGvHD; it is not exhaustive by any means, and many treatments are used following limited evidence from small non-randomised trials. The choice for further therapies is in most part governed by the features of cGvHD and the toxicities that may be inflicted as well as the availability of the drug locally. The lack of consistently effective treatment in this setting underscores the need for high-quality clinical trials. Please refer to local policies and guidance with respect to second-line and subsequent therapies.

Extracorporeal photopheresis (ECP) is widely used in mucocutaneous cGvHD as a second-line therapy in steroid refractory patients and has been shown to be effective in up to $80 \%$ of patients (Couriel et al. 2006b). A UK consensus paper supported the findings and recommended ECP use in this group, with paired sessions every 2 weeks with reassessment at 3 months (Scarisbrick et al. 2008).

Imatinib , a tyrosine kinase inhibitor licenced for use in chronic myeloid leukaemia (CML), has gained in popularity over the past few years. Experiments have shown reduction in fibrosis possibly from a dual inhibition process of transforming growth factor beta and platelet-derived growth factor pathways (Dignan et al. 2012).

Sirolimus mTOR inhibitors such as sirolimus may be used in combination with other agents but with caution in CNI due to increased risk of thrombotic microangiopathy and hyperlipidaemia.

Rituximab is commonly used in haematology for B-cell malignancy and is a potent anti-CD20 monoclonal antibody, and there is some limited evidence of its use in cGvHD for musculoskeletal and cutaneous manifestations (Dignan et al. 2012)

Mesenchymal stem cells (MSC) (Ringden and Keating 2011) have generated considerable interest in treatment of aGvHD following initial studies from the group at the Karolinska Institute. There was some evidence from early experiments that MSC worked in autoimmune disorders, and given the fact that cGvHD may resemble this in some ways, MSC have been used for cGvHD treatment but remain mainly within clinical trials.

Infliximab, an antitumour necrosis factor (TNF) antibody, is a chimeric human anti-TNFa-IgG1(j) monoclonal antibody that inhibits the binding of 
TNF to its cellular receptors and has been used in some cases of GI GvHD (Dignan et al. 2012).

Thalidomide inhibits angiogenesis, expression of adhesion molecules, TNFa, interleukin-6, interleukin-12 and nuclear factor kappa B activity. A randomised clinical trial of thalidomide, ciclosporin and prednisolone compared to ciclosporin and prednisolone did not show any additional benefit in the primary treatment of cGvHD. Thalidomide has significant side effects including constipation, neuropathy, neutropenia, thrombocytopenia, tiredness and thrombosis (Dignan et al. 2012).

\subsubsection{Topical Treatments for CGvHD of the Eyes}

The aim of treatment is to give symptomatic relief of dry eye and care should be co-ordinated with an experienced ophthalmologist. Focus is placed upon increasing ocular surface moisture via lubrication and decreasing tear evaporation and tear drainage from the eye and decreasing ocular surface inflammation. Preservative-free drops coat the eye surface minimising dry spots on the cornea, decreasing ocular symptoms and improving vision. It may take several different trials of drops to find one that works as patients may be more sensitive to one solution. Temporary (with punctual plugs) or permanent (with cauterisation) occlusion of the tear duct may offer a solution to those with severe dry eye. Where there is inflammation of the ocular surface, direct application of steroid eye drops may be beneficial especially if the patient is on a taper of systemic immunosuppression and the eye symptoms flare (Couriel et al. 2006b).

Ciclosporin eye drops appear to offer a solution, but they cause irritation in most patients, and thus compliance is poor. If available, autologous serum eye drops may decrease surface inflammation.

\subsubsection{Topical Treatments for Oral cGvHD}

Management of oral cGvHD aims to alleviate symptoms of dry mouth, sensitivity and pain whilst maintaining oral function and restoring mucosal integrity (Meier et al. 2011). It may appear obvious, but the single most important action for patients is to maintain good oral hygiene (daily care and regular dental visits). Children's toothpaste causes less irritation and should be used with a soft toothbrush, with the addition of lip salve if appropriate. Suggest also avoidance of potential triggers for flares of cGvHD such as spicy or hot food or sharp foodstuffs that can cause damage. Sip water and chew sugar-free gum to improve xerostomia.

Often patients require systemic therapy as multiple sites are involved. However, the oral cavity can be refractory to systemic therapy; thus complementary topical treatment is needed. There are a variety of topical steroid mouthwashes that are the first line of therapy, including prednisolone, budesonide or betamethasone. Tacrolimus $0.1 \%$ mouthwash is well tolerated and has shown to be an effective option and may be used alongside steroid mouthwashes as second-line therapy. It is important to describe adequately how to use these preparations as in many cases this is not their usual route of administration. Several centres in Europe have access to phototherapy with ultraviolet A and B light. This stems from work in cutaneous cGvHD. A glass fibre extension of an UVA source is used for manual intraoral application three to four times a week (Meier et al. 2011).

To relieve oral pain, topical application of local anaesthetics such as lidocaine can be applied, either as a gel, mouthwash or spray. These should be used with caution as the gag reflex may be compromised and lead to choking and aspiration.

\subsubsection{Ancillary and Supportive Care for CGvHD of the Skin}

Chronic GvHD of the skin remains the most affected organ and is often debilitating when in extremis. Topical treatments are a vital therapy in addressing the manifestations of itch, rash, pain and dyspigmentation, whilst the use of physical therapy helps patients with limited range of movement maintain some degree of functional- 
ity. Other healthcare providers such as tissue viability and infection control teams can offer help, guidance and support when skin becomes friable and breaks down leaving ulcers, erosions and superadded infections. The patient with cutaneous cGvHD is at an increased risk of skin cancer, and regular monitoring and assessment are advised. Any suspicion should be followed up with biopsy. Advice with respect to UV exposure should be given regularly: avoiding direct sun exposure and using sun blocks and sunscreens and loose fitting clothing with hat and glasses.

Emollients are the backbone of skin care to maintain the integrity of unbroken dry skin and can be applied frequently throughout the day. It is therefore important to work with the patient to ensure the prescribed product is one they are happy with and addresses their issues; otherwise they are unlikely to use it regularly enough for it to be effective (see section on aGvHD). It is worth noting they may need more than one product; areas of extreme scaling or with plaques, for example, will require an ointment (commonly on the lower limbs), whereas areas with delicate skin will require a lighter product (e.g. the face). Whilst emollients tend to be petroleum based, using a product which incorporates lipids (e.g. coconut oil in QV cream) will help 'nourish' the skin in addition to providing a barrier.

Topical steroids are initiated in a stepwise fashion, attempting to deliver the least potent steroid to achieve the result desired. Lower strength steroid hydrocortisone can be applied to the face as can Eumovate under strict supervision, whilst the more potent Dermovate and Betnovate should be applied to the body only.

Pruritis is common and can be a distressing symptom. Itch usually responds to systemic therapy, i.e. antihistamines; however, topical antipruritic with menthol such as Dermacool $(0.5-1 \%)$ may be applied if still problematic (Couriel et al. 2006b). It is important to note however that such products must be used with care. Widespread use can lead to alteration in thermoregulation, and the patient will feel very cold. It is therefore important to use a maximum of twice daily and on targeted areas only. Night time is often the worst, and as such, one application at bedtime may be sufficient.
Once the skin barrier has become breached, bacterial, viral and fungal tests should be taken and, if infection confirmed, treated rapidly. If swabs do not support an infective cause, it is important to rule out other pathologies; the ulcer may be as a consequence of vasculitis, malignancy, drug reaction or dermatitis and will need appropriate management (Couriel et al. 2006b).

One of the major challenges for topical management of chronic skin GvHD is the often severe sclerotic features - characterised by thickened, tight and fragile skin. This is often associated with poor wound healing, inadequate lymphatic drainage and skin ulcers from minor trauma or idiopathic origin. There is basic advice which should be given and regularly reinforced to all patients:

- Take care to minimise risk of bumps/knocks.

- Pat skin dry - no rubbing.

- Wear loose clothing to minimise risk of friction/irritation.

- Avoid the sun as much as possible.

- Maintain a good oral intake (water).

- Minimise/avoid the use of perfumes directly onto the skin (advise to spray onto clothes instead); make-up, if used, suggest minimal skin applications, researching into good quality products and protect the skin by initial application of a moisturiser.

- Provide clear, consistent and repeated reinforcement regarding the importance of regular use of emollients.

\subsubsection{Wound Care}

As previously stated, patients with cutaneous cGvHD are at high risk of skin breakdown. Any breaks must be taken seriously as they will quickly turn into chronic wounds if not managed effectively.

If a lesion is superficial, it may be possible to contain it by the use of a hydrocolloid dressing (e.g. DuoDerm extra thin). These are dressings which form a waterproof, protective layer over the lesion, are typically self-adhering and maintain a moist environment to encourage healing. They generally only require changing every 
3-4 days, so although they do absorb exudate, they would not be appropriate for a highly exuding wound. Equally, it is advisable to clean the wound with a topical antimicrobial solution (e.g. Octenilin) to minimise risk of high bacterial load in the wound bed. Because of the fragility of skin affected by cGvHD, to minimise risk of maceration and to facilitate adherence of the dressing, it is advisable to apply a barrier film (e.g. Cavilon or Sorbaderm) to the surrounding epithelium prior to application of the dressing.

In the case of cavity lesions, extra precautions are required. Wound healing in this patient cohort will commonly be slower (see below), and as such lesions are at risk of bacterial colonisation/infection thus further delaying the healing process.

Healing results from the interaction of platelets, with cells such as neutrophils, macrophages, fibroblasts and keratinocytes combined with extracellular matrix (ECM) components, such as fibronectin, tenascin and collagens. Interface with ECM components is regulated by mediators such as cytokines and growth factors (e.g. interleukins, interferons and TNF- $\alpha$ ) (Olczyk et al. 2014). The inflammatory response is triggered, and components such as growth factors facilitate proliferation, differentiation and metabolism of cells involved in the healing process. Others help regulate inflammatory processes and play a chemotactic role (encouraging cell movement) for neutrophils, macrophages, fibroblasts and epithelial cells (keratinocytes) to stimulate angiogenesis and the formation of ECM (Olczyk et al. 2014).

Because this cohort of patients will commonly be experiencing disruption to levels of the components required to facilitate healing due to systemic management of GvHD, wound healing becomes ever more complex and challenging.

In addition to the issue summarised above, if a wound becomes infected, this can initiate a 'flare' of acute GvHD requiring more intensive management and potentially compounding the situation.

Bioburden can be compounded if there is a significant amount of slough on the wound surface or in cases where the patient presents with a thick layer of eschar over the wound surface.

Debridement can contribute to a significant decrease in the bacterial load on the wound sur- face; there are several methods which can be used:

- Autolytic debridement (breakdown of bacterial cells), the use of moist dressing such as hydrogels or hydrocolloids may facilitate this.

- Surgical debridement, with scissors or scalpel, however this should be undertaken with caution and by experienced tissue viability nurses/ trained medical personnel.

- Mechanical debridement, pulse lavage, gentle washing, there are pulse lavage systems available; they have the benefit that they stimulate blood flow to the area, which can speed up granulation. Standing under the shower (especially a 'power shower') prior to dressing can have a similar effect, if the lesion is in an appropriate place.

- Biological debridement, with larvae of Lucilia sericata (green bottle fly). Use of larvae can be considered; however, it should only be used with the supervision of an experienced tissue viability nurse. Larvae of the green bottle fly, introduced into a wound (usually in a sterile bag), can remove necrotic, sloughy and/or infected tissue; they can also be used to maintain a clean wound after debridement. Larvae should only be considered when other avenues have been exhausted. They do not digest healthy tissue; however in some cases of cGvHD, the tissue in the wound bed has such a poor blood supply that it will not be differentiated by the larvae as healthy and they may start to digest it if not carefully supervised.

To pre-empt the risk of infection, there should be a very low threshold for using antimicrobial wound irrigation solution to cleanse wounds and surrounding skin. An additional precaution is to pack the wound with a hydrofibre (e.g. Aquacel), which turns into a gel on contact with exudate and contains any bacteria within the gel. These dressings can be obtained with ionic silver (Aquacel $\mathrm{Ag}$ ) to facilitate extra protection. If the wound is 'dry', dampen the hydrofibre prior to packing to prevent adherence to the wound bed. Although hydrofibres minimise the risk of maceration, it is still preferable to protect the surrounding skin with a barrier film; this will also facilitate adher- 
ence of the secondary dressing to the classically flaky skin of someone with cGvHD.

If the wound is not responding, collagen dressings can be used to try and facilitate effective healing (e.g. Promogran Prisma). Collagen is a key component of a healing wound. Due to issues such as bioburden, repeated trauma and ongoing immunosuppression, wounds in the patient with cGvHD can halt at the inflammatory phase, thus compounding the chronicity of the wound and impeding the formation of the 'scaffold' needed for cell migration. This will ultimately limit any formation of extracellular matrix (ECM) and granulation tissue (Brett 2008). Collagen-based wound dressings are uniquely suited to address this issue by acting as a substitute substrate, plus collagen breakdown products are chemotactic for cells required for the formation of granulation tissue (Brett 2008). In addition, collagen-based dressings have the ability to absorb wound exudate and maintain a moist wound environment and do not require removal at subsequent dressing changes. However, it is important to note that they remain inactive when dry, so where there is minimal exudate in the wound, it is important to dampen them before application.

\subsection{Vulvovaginal GvHD}

As with cGvHD in other parts of the body, symptoms associated with vulvovaginal GvHD (vv GvHD) may be attributable to other pathologies; Candida infection, for example, can cause discharge or itch, whilst hormone reduction/ menopause may be responsible for vaginal dryness/soreness. Such co-morbidities require diagnosis and appropriate treatment.

In women with chronic vvGvHD, mechanical and chemical irritants should be avoided. Washing with warm water, using products from such ranges as Oilatum or Dermol if required (rather than soap), cleaning in a front-to-back direction and then air-dried is to be advised. Bacteriostatic gels such as Replens may be used in the vagina for comfort as this adheres to the vaginal wall and has a long-lasting effect. Vulval and vaginal topical management can include steroid/immunosuppressant cream. In extreme cases, surgical interven- tions may be required to release strictures and adhesion formation. In all cases, particularly if the woman is not sexually active, dilators lubricated with, for example, a lipid, such as coconut oil, should be thought about as a way of maintaining vaginal patency and capacity.

Crucially, it is important that these matters are addressed in a sensitive manner as there is often a psychological impact and it may be affecting any partnership the patient is in. For this reason, anyone working with these women needs to be skilled in offering them the opportunity to disclose any emotional concerns and, if necessary, refer them for expert counselling.

Body image and sexual dysfunction are significant problems for both men and women posttransplant and are especially problematic upon development of cGvHD. Counselling and early involvement with psych-oncology services are important to aid in maintaining normality in an abnormal situation.

\subsection{Chronic Lung GvHD}

Chronic lung GvHD may be treated with bronchodilators, inhaled corticosteroids, systemic steroids, montelukast and referral to a physical rehabilitation programme (Couriel et al. 2006b). Lung GvHD has a somewhat dismal outcome as it is not very responsive to any modality. Nurses and physiotherapists can help patients manage the distress and possible panic situations the patient may feel due to increasing breathlessness, by teaching complementary self-management skills such as breathing techniques, focused relaxation and stress management.

\subsection{Connective Tissue Involvement in CGvHD}

Patients with cGvHD affecting skin, joints and connective tissue will benefit from inclusion in an exercise rehabilitation programme along with occupational therapy. Functional losses associated with muscle loss, weakness, contractures and limb swelling lead to fatigue and a decreased ability to perform activities of daily living and 
often preclude patients from being able to return to work. Rehabilitation should aim to improve strength and mobility of joints and muscles and ideally should occur before permanent and lasting damage has set in (Couriel et al. 2006b). Such programmes should include family members where possible, as exercises need to be carried out on a regular basis to be effective, with the patient often needing support to do this. It can also be psychologically helpful to any family/ carers involved as it allows them to feel confident to be part of the care of their loved one.

In addition to exercise, regular massage can help maintain flexibility and function of affected limbs. If there is fascial involvement, any massage provided will need to access these tissue layers to be effective. It is therefore important that the therapist providing this treatment has been trained in using such techniques. Again, it is possible to teach family members appropriate massage skills, which will improve the efficacy of therapy provided.

\subsection{Quality of Life}

QoL is severely compromised in cGvHD, with reports of fatigue, pain and GI upset. FACT-BMT QoL questionnaire studies have revealed that physical, sexual and social functioning is also lower with higher rates of depression and anxiety and adverse effects on social and family interactions. Depressive symptoms are more severe and last longer and often manifest when patients complain of loss of memory or poor concentration. Fatigue may be considered as a separate entity but is often mixed in with QoL, anxiety and depression. It may be described as a persistent and subjective state of tiredness that interferes with usual functioning and can continue for several years after transplant (Couriel et al. 2006b). Using questionnaires to assess these issues with individual patients is something which nurses can instigate to identify the impact of psychological morbidity in specific cases. These can be used as a framework to enable patients to express their concerns and structure a support programme to help manage specific issues - including onward referrals to appropriate professionals.

\subsection{The Future}

Considering the increased utilisation of HSCT, the morbidity and mortality associated with GvHD and the limitations inherent to contemporary therapies, novel approaches are urgently needed. Rationally designed treatments that inhibit deregulated pathways in malignant cells are typically the focus of 'targeted' therapy. In GvHD, the 'target' is elusive, as the goal is to carefully contain an overzealous but biologically normal immunologic response (Magenau and Reddy 2014). Success in prophylaxis and treatment of GvHD will depend on whether GvHD can be prevented without losing the antitumour effect. Improvements in the understanding of the pathophysiology will move clinicians towards this goal. Risk stratification and the emergence of a bedside GvHD test based on proteomics may be on the horizon and will ultimately then improve the outlook for this difficult-to-treat group of patients (Greinix 2008).

\subsection{GvHD in Children}

Data and research on GvHD in the paediatric population are limited with only a few studies specifically focused on children. Most studies are small, and children are often grouped into larger adult series (Baird et al. 2010). In this short review, we will emphasise on the specific aspects of paediatric GvHD primarily focusing on cGvHD.

Most of the literature on cGvHD has focused on adults. Although the clinical manifestation of cGvHD in children is similar to that in adults, the consequences of treatment and nonresponses are remarkably different in a growing organism (Lawitschka et al. 2012). Children with cGvHD are of particular interest, given their longer life expectancy and developmental issues following the complications of cGvHD and its therapy (Jacobsohn 2010; Jacobsohn et al. 2011). Compared with childhood cancer survivors who did not undergo transplantation, HSCT survivors have a substantially increased 
burden of serious chronic conditions and impairments involving every organ. A history of GvHD or presence of cGvHD contributes to increase rate of long-term complications in the paediatric transplant survivors (Chow et al. 2016). Chronic GvHD has negative effects on an individual's physical and mental health and can lead to the development of functional impairments and activity limitations over their lifetime (Baird et al. 2010) as well as reduced quality of life (Inagaki et al. 2015). However, paediatric cGvHD remains an understudied area of research (Jacobsohn et al. 2011); therefore, large paediatric multicentre studies are needed (Watkins et al. 2016).

\subsubsection{Incidence and Risk Factors}

Overall the rates of cGvHD are lower in children than adults (Champlin et al. 2000; Rocha et al. 2000). However, the incidence of cGvHD in the paediatric population is still substantial and has increased recently in association with the expanded use of peripheral blood stem cells and unrelated donors (Baird et al. 2010). Zecca et al. (2002) in a large paediatric study reported a cumulative probability of cGvHD of $27 \%$; this probability is nearly half of the estimated probability of 40-50\% described in adults. Flowers et al. (2011) published a large single-centre study of risk factors for aGvHD and cGvHD. The sample included both adult and paediatric patients; cGvHD was defined according to the NIH cGvHD criteria (Filipovich et al. 2005). The incidence of moderate to severe cGvHD in the paediatric patient was $28 \%$ (Watkins et al. 2016).

The risk factors for cGvHD in childhood are still poorly defined. Zecca et al. (2002) reported the risk factors associated with cGvHD in children: male patients transplanted from a female donor experience more cGvHD. Children with nonmalignant disorders had a reduced risk of developing cGvHD. This might be due to the fact that children with these diseases do not benefit from GvHD since they do not need any graft-versusmalignancy effect, and therefore the most effective pharmacologic strategies for both prevention and treatment of aGvHD were used in these patients. The condition of mixed donor chimerism is associated with reduced susceptibility to GvHD. Some of the children with non-malignant disorders (those with aplastic anaemia or with congenital immunodeficiencies) are given less intensive preparative regimens, and it has been hypothesised that the cytokine storm, which is dependent on the intensity of the conditioning regimen, triggers development of GvHD. Malignant diseases and the use of myeloablative protocol as well as TBI as part of the preparative regimen have an increased risk of classic aGvHD (Faraci et al. 2012). Older recipient and donor ages are another risk factor for cGvHD (Watkins et al. 2016).

\subsubsection{Treatment}

The major emphasis in GvHD has been on prevention, as results with treatment have been disappointing. Currently most centres use a combination of a calcineurin inhibitor (ciclosporin or tacrolimus) with short-course methotrexate (Jacobsohn 2008).

The treatment of cGvHD in paediatrics is highly variable and mostly extrapolated from the experience in adults. Although there is no proven standard therapy, prednisolone and ciclosporin are commonly used as frontline therapy. As steroids remain the basis of cGvHD therapy, the consequences of long-term steroid use in children are well described, and long-term harmful effects on growth and bone density persist even after discontinuation of therapy.

Other potential treatment strategies include extracorporeal photopheresis (as discussed earlier in this chapter) and the infusion of allogeneic human mesenchymal stem cells (MSC) for the treatment of aGvHD and cGvHD. Multiple MSC infusions are safe and effective for children with steroid-refractory aGvHD, especially when employed early in the disease course. Early treatment may be associated with reduced treatmentrelated mortality and better overall survival (Ball et al. 2013). MSC offer new potential modalities of treatments for paediatric cGvHD refractory to 
standard treatments (Lawitschka et al. 2012). The treatment in paediatric patients must take into consideration the potential effect on growth, nutrition, organ function, bone metabolism, hormonal balance, psychosocial aspects and immune reconstitution (Baird et al. 2010; Lawitschka et al. 2012).

The nursing management and care of children with GvHD are complex and require expert skills and knowledge as well as adjustment to the child/ adolescent developmental need. Patients and families, who initially felt great relief to be cured from their primary disease, now face the challenge of a chronic devastating illness for which preventative and treatment strategies are suboptimal (Baird et al. 2010). The treatment and support of the children and their families require a multidisciplinary team care that will be able to provide a comprehensive response to all their needs.

\section{Appendix}

\section{Appendix 1: Classification of Patients with Acute GVHD}

\begin{tabular}{|c|c|c|c|}
\hline Stage & $\begin{array}{l}\text { Skin/maculopapular rash } \\
\text { BSA }\end{array}$ & $\begin{array}{l}\text { Liver bilirubin } \\
(\mathrm{mg} / \mathrm{dl})\end{array}$ & Gut (ml diarrhoea/day) \\
\hline 0 & No rash & $<34 \mathrm{umol} / \mathrm{L}$ & $<500 \mathrm{ml} /$ day \\
\hline 1 & $<25 \%$ of body surface area & $34-50 \mathrm{umol} / \mathrm{L}$ & $\begin{array}{l}>500-999 \mathrm{ml} / \text { day or persistent } \\
\text { nausea with histological evidence } \\
\text { stomach/duodenum }\end{array}$ \\
\hline 2 & $25-50 \%$ of body surface area & 51-102 umol/L & $1000-1500 \mathrm{ml} /$ day \\
\hline 3 & $>50 \%$ of body surface area & $103-255 \mathrm{umol} / \mathrm{L}$ & $>1500 \mathrm{ml} /$ day \\
\hline 4 & $\begin{array}{l}\text { Generalised erythroderma with } \\
\text { bullous formation and } \\
\text { desquamation }\end{array}$ & $>255 \mathrm{umol} / \mathrm{L}$ & $\begin{array}{l}\text { Severe abdominal pain with or } \\
\text { without ileus }\end{array}$ \\
\hline
\end{tabular}

\begin{tabular}{l|l|l|l|}
$\begin{array}{l}\text { Acute GvHD clinical grading modified Glucksberg/ } \\
\text { keystone criteria }\end{array}$ \\
\hline Grade & Skin & Liver & Gut \\
\hline 0 & None & None & None \\
\hline I & Stages $1-2$ & None & None \\
\hline II & Stage 3 & Stage 1 & Stage 1 \\
III & - & Stages $2-3$ & Stages 2-4 \\
IV & Stage 4 & Stage 4 & - \\
\hline
\end{tabular}

Glucksberg et al. (1974) modified criteria taken from the EBMT 2008 revised edition of handbook with permission 


\section{Appendix 2: Scoring of Chronic GvHD}

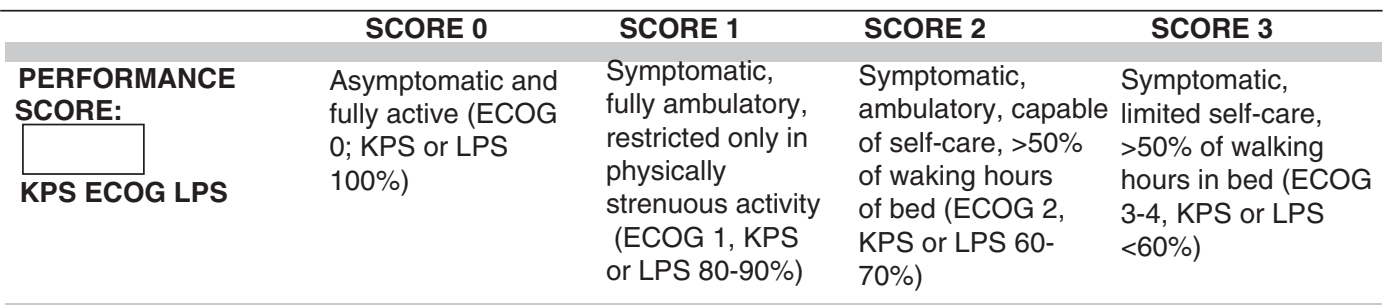

\section{SKIN † \\ SCORE \% BSA}

GVHD features to be scored by $B S A$ :

No BSA $\quad 1-18 \%$ BSA $\quad 19-50 \%$ BSA $\quad>50 \%$ BSA

Check all that apply:

Maculopapular rash/erythema

Lichen planus-like features

Sclerotic features

Papulosquamous lesions or

ichthyosis

Keratosis pilaris-like GVHD

\begin{tabular}{ll}
\hline SKIN FEATURES & $\begin{array}{l}\text { No sclerotic } \\
\text { features }\end{array}$ \\
SCORE: & f
\end{tabular}

features
Superficial sclerotic features "not hidebound" (able to pinch)

Check all that apply:
Deep sclerotic
features
"Hidebound"
(unable to pinch)
Impaired mobility
Ulceration

Other skin GVHD features (NOT scored by BSA)

Check all that apply:

Hyperpigmentation

Hypopigmentation

Poikiloderma

Severe or generalized pruritus

Hair involvement

Nail involvement

Abnormality present but explained entirely by non-GVHD documented cause (specify):

\begin{tabular}{|c|c|c|c|c|}
\hline $\begin{array}{l}\text { MOUTH } \\
\text { Lichen planus-like } \\
\text { features present: } \\
\text { Yes } \\
\text { No }\end{array}$ & No symptoms & $\begin{array}{l}\quad \text { Mild symptoms } \\
\text { with disease signs } \\
\text { but not limiting } \\
\text { oral intake } \\
\text { significantly }\end{array}$ & \begin{tabular}{l}
\multicolumn{1}{c}{ Moderate } \\
symptoms with \\
disease signs with \\
partial limitation \\
of oral intake
\end{tabular} & $\begin{array}{l}\text { Severe symptoms with } \\
\text { disease signs on } \\
\text { examination with major } \\
\text { limitation of oral intake }\end{array}$ \\
\hline
\end{tabular}




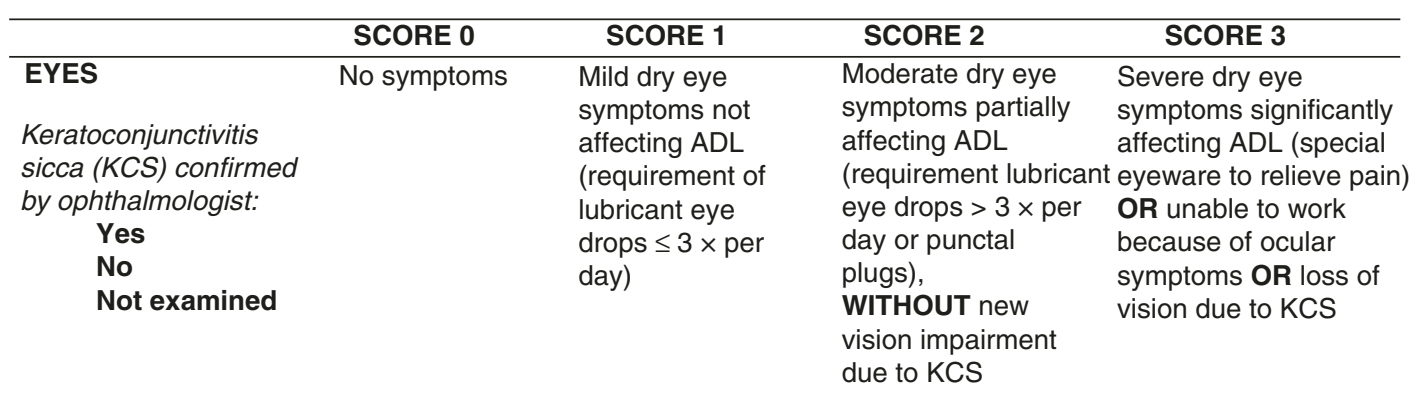

Abnormality present but explained entirely by non-GVHD documented cause (specify):

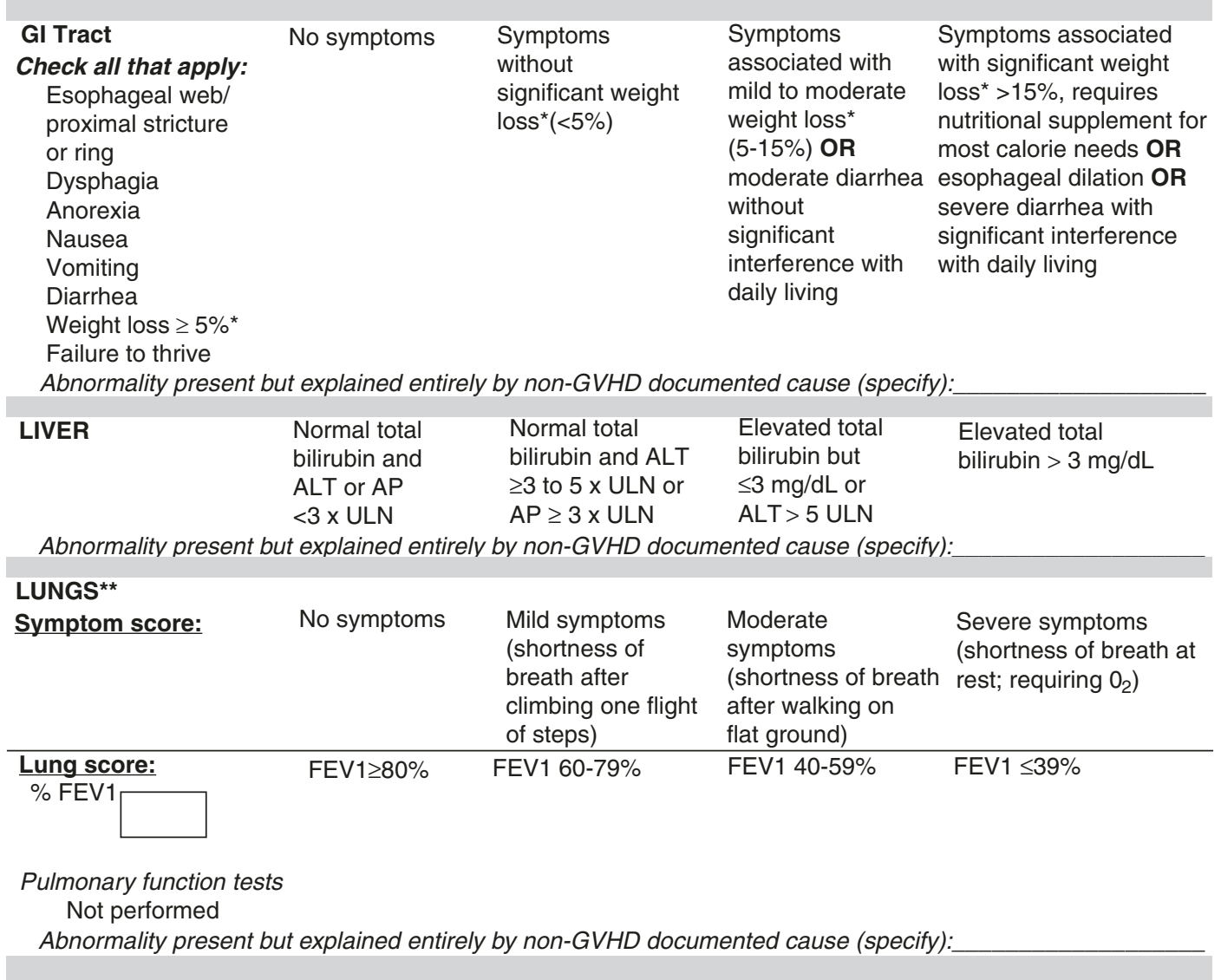




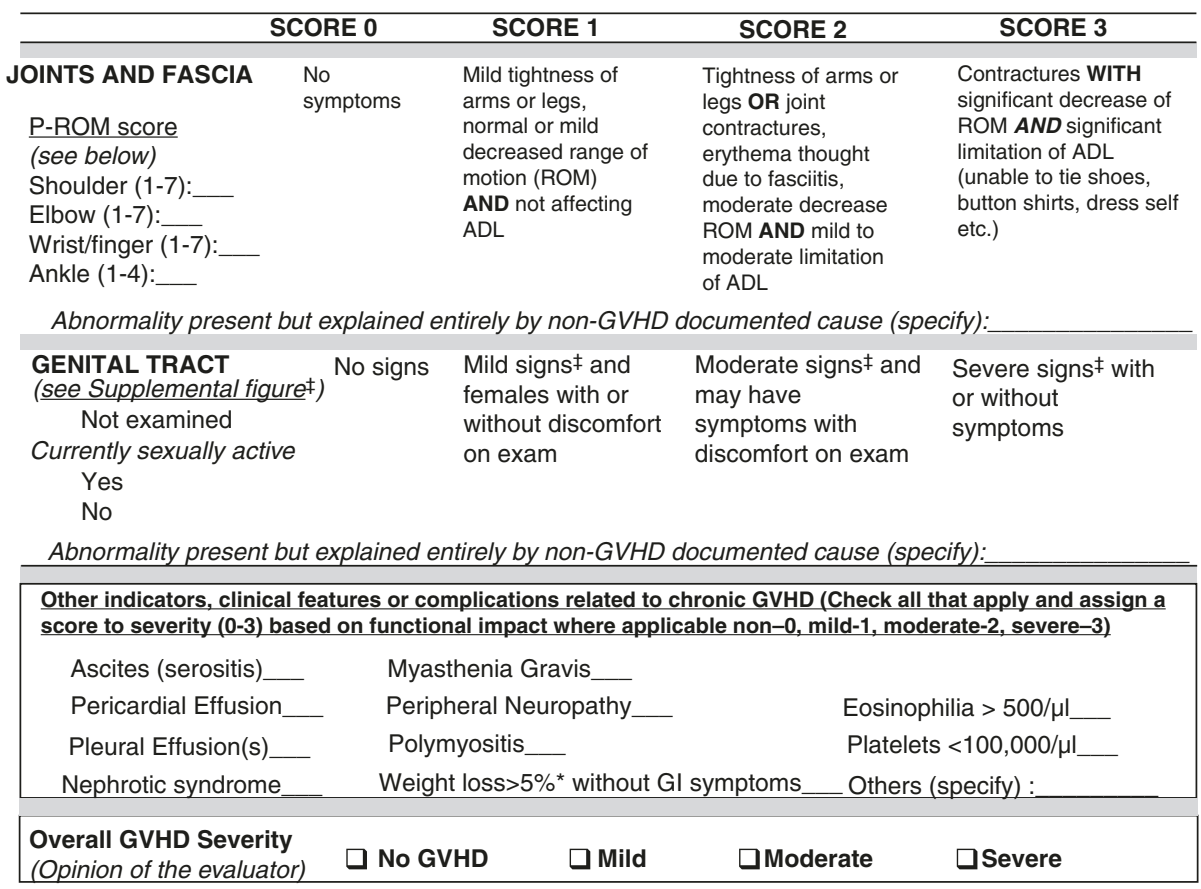

Photographic Range of Motion (P-ROM)

† Skin scoring should use both percentage of BSA involved by disease signs and the cutaneous features scales. When a Discrepancy exists between the percentage of total body surface (BSA) score and the skin feature score, OR if superficial sclerotic features are present (Score 2), but there is impaired mobility or ulceration (Score 3), the higher level should be used for the final skin scoring.

* Weight loss within 3 months.

** Lung scoring should be performed using both the symptoms and FEV1 scores whenever possible. FEV1 should be used in the final lung scoring where there is discrepancy between symptoms and FEV1 scores.

Abbreviations: ECOG (Eastern Cooperative Oncology Group), KPS(Karnofsky Performance Status), LPS(Lansky Performance Status); BSA(body surface area); ADL(activities of daily living); LFTs(liver function tests); AP (alkaline phosphatase); ALT (alanine aminotransferase); ULN(normal upper limit).

$\ddagger$ To be completed by specialist or trained medical providers (see Supplemental Figure). 
Name:

Date of birth:

Assessment date:

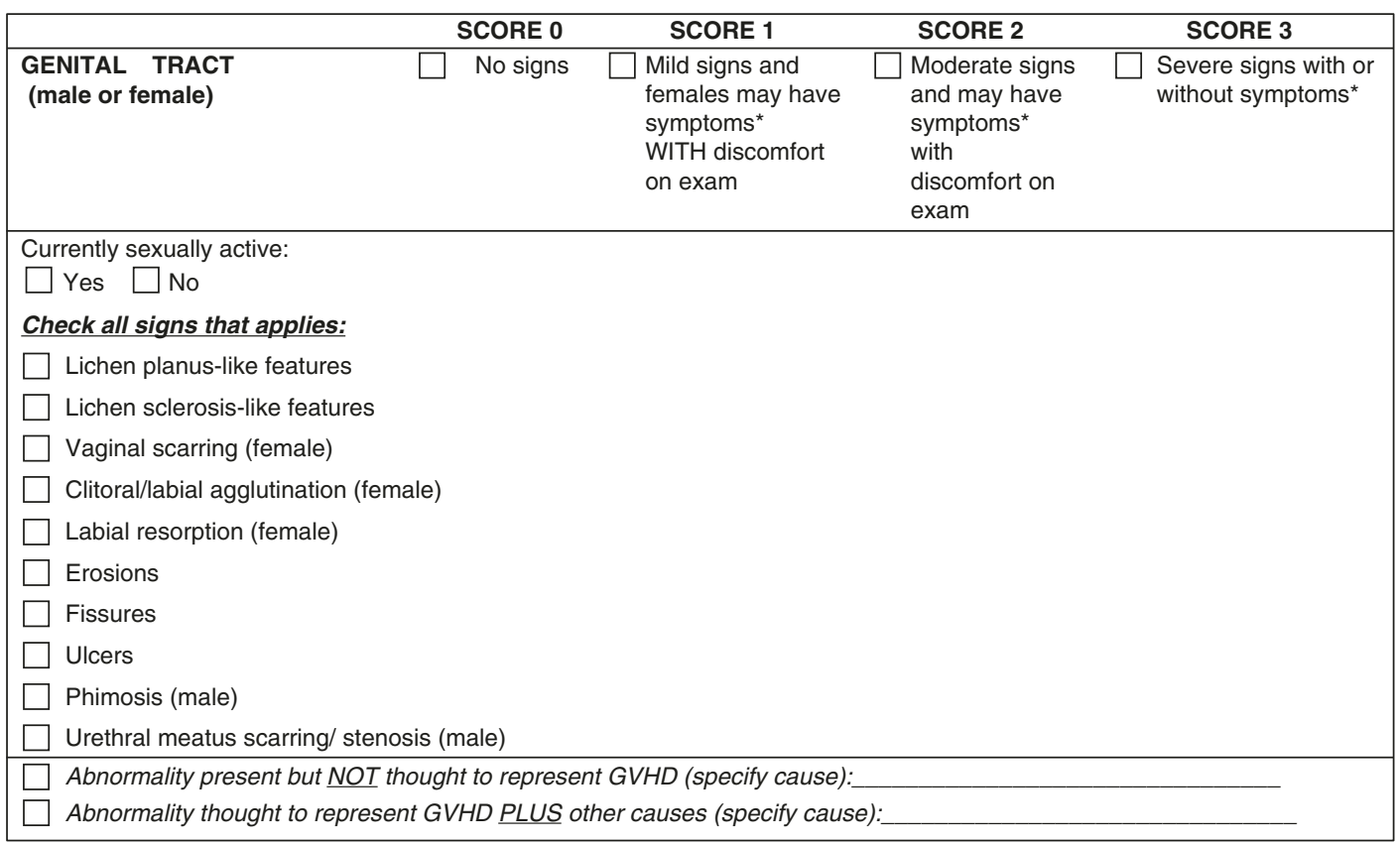

* Genital symptoms are not specific to cGVHD and can represent premature gonadal failure or genital tract infection.

If a gynecologist is unavailable, external examination may be performed to determine "discomfort on exam" as follows:

a) Spread the labia majora to inspect the vulva for the above signs. Touch the vestibular gland openings (Skene's and Bartholin's), labia minora and majora gently with a qtip. Vulvar pain elicited by the gentle touch of a qtip is classified as discomfort on examination. Palpate the vaginal walls with a single digit to detect bands, shortening, narrowing or other signs of vaginal scarring.

b) If the woman is sexually active, determine whether qtip palpation or gentle palpation of scarred ridges elicits pain similar to that which the woman experiences during intercourse.

Female genitalia: Severity of signs:

1) Mild (any of the following); erythema on vulvar mucosal surfaces, vulvar lichen-planus or vulvar lichen-sclerosis

2) Moderate (any of the following); erosive inflammatory changes of the vulvar mucosa, fissures in vulvar folds

3) Severe (any of the following); labial fusion, clitoral hood agglutination, fibrinous vaginal adhesions, circumferential fibrous vaginal banding, vaginal shortening, synechia, dense sclerotic changes, and complete vaginal stenosis

Male genitalia: Diagnostic features include lichen planus-like or lichen sclerosis-like features and phymosis or urethral scarring or stenosis. Severity of signs: Mild - lichen planus-like feature; Moderate - lichen sclerosis-like feature or moderate erythema; Severe - phimosis or urethral/meatal scarring

Biopsy obtained: $\square$ Yes $\square$ No Site biopsied:_ GVHD confirmed by histology: $\square$ Yes $\square$ No
Change from previous evaluation: $\square$ No prior or current GVHD $\square$ Improved $\square$ Stable $\square$ Worse $\square$ N/A (baseline)

Jagasia et al. (2015) with permission

\section{References}

Al-Kadhimi ZG, Chen W, Smith D, Abid M, Deol A, Ayash L, Lum L, Waller EK, Ratanatharathorn V, Uberti J. High incidence of severe acute graft-versushost disease with tacrolimus and mycophenolate mofetil in a large cohort of related and unrelated allo- geneic transplantation patients. Biol Blood Marrow Transplant. 2014;20:979-85.

Baird K, Cooke K, Schultz KR. Chronic graft-versushost disease (GvHD) in children. Pediatr Clin N Am. 2010;57:297-322.

Ball LM, et al. Multiple infusions of mesenchymal stromal cells induce sustained remission in children with steroid-refractory, grade III-IV acute graft-versushost disease. Br J Haematol. 2013;163:501-9.

Baron F, Labopin M, Niederwieser D, Vigouroux S, Cornelissen JJ, Malm C, Vindelov LL, Blaise D, Janssen JJWM, Petersen E, Socie' G, Nagler A, 
Rocha V, Mohty M. Impact of graft-versus-host disease after reduced-intensity conditioning allogeneic stem cell transplantation for acute myeloid leukemia: a report from the Acute Leukemia Working Party of the European group for blood and marrow transplantation. Leukemia. 2012;26:2462-8.

Bladon J, Taylor P. The down regulation of IL1 and IL6, in monocytes exposed to ECP treated lymphocytes, is not dependent on lymphocyte phosphatidylserine externalisation. Transpl Int. 2006;19(4):319-24.

Billingham RE. The biology of graft-versus-host reactions. Harvey Lect. 1966-7;62:71-8.

Brett D. Review of collagen and collagen-based wound dressings. Wounds. 2008;20(12):347-56

Carpenter P. How I conduct a comprehensive chronic graft-versus-host disease assessment. Blood. 2011;118(10):2679-87.

Chow EJ, Anderson L, Baker KS, et al. Late effects surveillance recommendations among survivors of childhood hematopoietic cell transplantation: a children's oncology group report. Biol Blood Marrow Transplant. 2016;22:782-95.

Champlin RE, Schmitz N, Horowitz MM, et al. Blood stem cells compared with bone marrow as a source of hematopoietic cells for allogeneic transplantation. IBMTR Histocompatibility and Stem Cell Sources Working Committee and the European Group for Blood and Marrow Transplantation (EBMT). Blood. 2000;95:3702-9.

Couriel D, Carpenter PA, Cutler C, Bolaños-Meade J, Treister NS, Gea-Banacloche J, Shaughnessy P, Hymes S, Kim S, Wayne AS, Chien JW, Neumann J, Mitchell S, Syrjala K, Moravec CK, Abramovitz L, Liebermann J, Berger A, Gerber L, Schubert M, Filipovich AH, Weisdorf D, Schubert MM, Shulman H, Schultz K, Mittelman B, Pavletic S, Vogelsang GB, Martin PJ, Lee SJ, Flowers MED. Ancillary therapy and supportive care of chronic graft-versus-host disease: National Institutes of Health consensus development project on criteria for clinical trials in chronic graft-versus-host disease: V. ancillary therapy and supportive care working group report. Biol Blood Marrow Transplant. 2006a;12: 375-96.

Couriel DR, Hosing C, Saliba R, Shpall EJ, Anderlini P, Rhodes B, Smith V, Khouri I, Giralt S, de Lima M, Hsu Y, Ghosh S, Neumann J, Andersson B, Qazilbash M, Hymes S, Kim S, Champlin R, Donato M. Extracorporeal photochemotherapy for the treatment of steroid-resistant chronic GVHD. Blood. 2006b;107:3074-80.

Dignan FL, Clark A, Amrolia P, Cornish J, Jackson G, Mahendra P, Scarisbrick JJ, Taylor PC, Hadzic N, Shaw BE, Potter MN, On behalf of the Haematooncology Task Force of the British Committee for Standards in Haematology and the British Society for Blood and Marrow Transplantation. Diagnosis and management of acute graft-versus-host disease. Br J Haematol. 2012;158(1):30-45.
Flowers MED, Inamoto Y, Carpenter PA, Lee SJ, et al. Comparative analysis of risk factors for acute graftversus-host disease and for chronic graft-versus-host disease according to National Institutes of Health consensus criteria. Blood. 2011;117:3214-9.

Flowers MED, Martin PJ. How we treat chronic graft versus host disease. Blood. 2015;125(4):606-15.

Filipovich AH, Weisdorf D, Pavletic S, et al. National Institutes of Health consensus development project on criteria for clinical trials in chronic graft-versushost disease: I. Diagnosis and staging working group report. Biol Blood Marrow Transplant. 2005;11(12): 945-56.

Faraci M, Caviglia I, Biral E, et al. Acute graft-versus-host disease in pediatric allogeneic hematopoietic stem cell transplantation. Single-center experience during $10 \mathrm{yr}$. Pediatr Transplant. 2012;16:887-93.

Ferrara JL, Deeg HJ. Graft-versus-host disease. N Engl J Med. 1991;324:667-74.

Glucksberg H, Storb R, Fefer A, Buckner CD, Neiman PE, Clift RA, Lerner KG, Thomas ED. Clinical manifestations of graft-versus-host disease in human recipients of marrow from HL-A-matched sibling donors. Transplantation. 1974;18:295-304.

Greinix HT. Graft-versus-host disease. Bremen: UNIMED Verlag AG; 2008.

Hill GR, Ferrara JLM. The primacy of the gastrointestinal tract as a target organ of acute graft-versus-host disease: rationale for the use of cytokine shields in allogeneic bone marrow transplantation. Blood. 2000;95:2754-9.

Inagaki J, Moritake $\mathrm{H}$, Nishikawa $\mathrm{T}$, et al. Long-term morbidity and mortality in children with chronic graftversus-host disease classified by National Institutes of Health consensus criteria after allogeneic hematopoietic stem cell transplantation. Biol Blood Marrow Transplant. 2015;21:1973-80.

Jacobsohn DA. Acute graft-versus-host disease in children. Bone Marrow Transplant. 2008;41:215-21.

Jacobsohn DA. Optimal management of chronic graftversus-host disease in children. $\mathrm{Br} \mathrm{J}$ Haematol. 2010;150:278-92.

Jacobsohn DA, Arora M, Klein JP, et al. Risk factors associated with increased nonrelapse mortality and with poor overall survival in children with chronic graftversus-host disease. Blood. 2011;118(16):4472-9.

Jacobsohn DA, Vogelsang GB. Acute graft versus host disease. Orphanet J Rare Dis. 2007;2:35.

Jagasia MH, Greinix HT, Arora M, Williams KM, Wolff D, Cowen EW, Palmer J, Weisdorf D, Treister NS, Cheng S, Kerr H, Stratton P, Duarte RF, McDonald GB, Inamoto Y, Vigorito A, Arai S, Datiles MB, Jacobsohn D, Heller T, Kitko CL, Mitchell SA, Martin PJ, Shulman H, Wu RS, Cutler CS, Vogelsang GB, Lee SJ, Pavletic SZ, Flowers MED. National Institutes of Health chronic graft-versus-host disease consensus for clinical trials: I. The 2014 diagnosis and staging working group report. Biol Blood Marrow Transplant. 2015;21(3):389-401. 
Kuzmina Z, Greinix HT, Weigl R, Körmöczi U, Rottal A, Frantal S, Eder S, Pickl WF. Significant differences in B-cell subpopulations characterize patients with chronic graft-versus-host disease-associated dysgammaglobulinemia. Blood. 2011;117(7):2265-74.

Lawitschka A, Ball LM, Peters C. Nonpharmacologic treatment of chronic graft-versus-host disease in children and adolescents. Biol Blood Marrow Transplant. 2012;18:S74-81.

Lee SJ, Vogelsang G, Flowers MED. Chronic graftversus-host disease. Biol Blood Marrow Transplant. 2003;9:215-33.

Lee SJ, Flowers MED. Recognizing and managing chronic graft-versus-host disease. In: Gewirtz AM, Muchmore EA, Burns LJ, editors. Haematology 2008: American Society of Haematology Education Program Book. Washington, DC: American Society of Haematology; 2008. p. 134-41.

Magenau J, Reddy P. Next generation treatment of acute graft-versus-host disease. Leukaemia. 2014;28:2283-91.

Martin PJ, Weisdorf D, Przepiorka D, Hirschfeld S, Farrell A, Rizzo JD, Foley R, Socie G, Carter S, Couriel D, Schultz KR, Flowers MED, Filipovich AH, Saliba R, Vogelsang GB, Pavletic SZ, Lee SJ. National Institutes of Health consensus development project on criteria for clinical trials in chronic graft-versus-host disease: VI. Design of clinical trials working group report. Biol Blood Marrow Transplant. 2006;12:491-505.

Meier JKH, Wolff D, Pavletic S, Greinix H, Gosau M, Bertz H, Lee SJ, Lawitschka A, Elad S. Oral chronic graft-versus-host disease: report from the international consensus conference on clinical practice in cGVHD. Clin Oral Invest. 2011;15:127-39.

Olczyk P, Mencner Ł, Komosinska-Vassev K. The role of the extracellular matrix components in cutaneous wound healing. BioMed Res Int. 2014. Published online 2014 Mar 17

Pavletic SZ, Martin P, Lee SJ, Mitchell S, Jacobsohn D, Cowen EW, Turner ML, Akpek G, Gilman A, McDonald G, Schubert M, Berger A, Bross P, Chien JW, Couriel D, Dunn JP, Fall-Dickson J, Farrell A, Flowers MED, Greinix H, Hirschfeld S, Gerber L, Kim S, Knobler R, Lachenbruch PA, Miller FW, Mittleman B, Papadopoulos E, Parsons SK, Przepiorka D, Robinson M, Ward M, Reeve B, Rider LG, Shulman H, Schultz KR, Weisdorf D, Vogelsang GB. Measuring therapeutic response in chronic graft-versus-host disease: National Institutes of Health consensus development project on criteria for clinical trials in chronic graft-versus-host disease: IV. Response criteria working group report. Biol Blood Marrow Transplant. 2006;12:252-66.

Przepiorka D, Weisdorf D, Martin P, Klingemann HG, Beatty P, Hows J, Thomas ED. 1994 consensus con- ference on AGvHD grading. Bone Marrow Transplant. 1995;15:825-8.

Ringden O, Keating A. Mesenchymal stromal cells as treatment for chronic GVHD. Bone Marrow Transplant. 2011;46:163-64

Rocha V, Wagner JE Jr, Sobocinski KA, et al. Graftversus-host disease in children who have received a cord-blood or bone marrow transplant from an HLA identical sibling. Eurocord and International Bone Marrow Transplant Registry Working Committee on Alternative Donor and Stem Cell Sources. N Engl J Med. 2000;342:1846-54.

Scarisbrick JJ, Taylor P, Holtick U, Makar Y, Douglas K, Berlin G, Juvonen E, Marshall S, Photopheresis Expert Group. U.K. consensus statement on the use of extracorporeal photopheresis for treatment of cutaneous T-cell lymphoma and chronic graft-versus-host disease. Br J Dermatol. 2008;158:659-78.

Shulman HM, Sullivan KM, Weiden PL, McDonald GB, Striker GE, Sale GE, Hackman R, Tsoi MS, Storb R, Thomas ED. Chronic graft-versus-host syndrome in man. A long-term clinicopathologic study of 20 Seattle patients. Am J Med. 1980;69:204-17.

Treister N, Chai X, Kurland B, Pavletic S, Weisdorf D, Pidala J, Palmer J, Martin P, Inamoto Y, Arora M, Flowers M, Jacobsohn D, Jagasia M, Arai S, Lee SJ, Cutler C. Measurement of oral chronic GVHD: results from the chronic GVHD consortium. Bone Marrow Transplant. 2013;48:1123-8.

Vigorito AC, Campregher PV, Storer BE, Carpenter PA, Moravec CK, Kiem HP, Fero ML, Fero ML, Warren EH, Lee SJ, Applebaum FR, Martin PJ, Flowers MED. Evaluation of NIH consensus criteria for classification of late acute and chronic GvHD. Blood. 2009;114(3):702-8.

Watkins BK, Horan J, Storer B, Martin PJ, Carpenter PA, Flowers MED. Recipient and donor age impact the risk of developing chronic GvHD in children after allogeneic hematopoietic transplant. Bone Marrow Transplant. 2016;52(4):625-626. 1-2 advance online publication 19 December 2016. https://doi. org/10.1038/bmt.2016.328.

Weisdorf D, Haake R, Blazar B, Miller W, McGlave P, Ramsay N, Kersey J, Filipovich A. Treatment of moderate/severe acute graft-versus-host disease after allogeneic bone marrow transplantation: an analysis of clinical risk features and outcome. Blood. 1990;75:1024-30.

Wolf D, von Lilienfeld-Toal M, Wolf AM, Schleuning M, von Bergwelt-Baildon M, Held SEA, Brossart P. Novel treatment concepts for graft-versus-host disease. Blood. 2012;119(1):16-25.

Zecca M, Prete A, Rondelli R, Lanino E, Balduzzi A, Messina $\mathrm{C}$, et al. Chronic graftversus-host disease in children: incidence, risk factors, and impact on outcome. Blood. 2002;100:1192-200. 
Open Access This chapter is licensed under the terms of the Creative Commons Attribution 4.0 International License (http://creativecommons.org/licenses/by/4.0/), which permits use, sharing, adaptation, distribution and reproduction in any medium or format, as long as you give appropriate credit to the original author(s) and the source, provide a link to the Creative Commons license and indicate if changes were made.

The images or other third party material in this chapter are included in the chapter's Creative Commons license, unless indicated otherwise in a credit line to the material. If material is not included in the chapter's Creative Commons license and your intended use is not permitted by statutory regulation or exceeds the permitted use, you will need to obtain permission directly from the copyright holder. 